\title{
Inner-shell excitation spectroscopy of peroxides
}

\author{
K.L. Harding, S. Kalirai, R. Hayes, V. Ju, G. Cooper, A. P. Hitchcock ${ }^{(*)}$ \\ Dept. of Chemistry and Chemical Biology, McMaster University, Hamilton, ON, L8S 4M1 Canada \\ and \\ M. R. Thompson \\ Dept. of Chemical Engineering, McMaster University, Hamilton, ON, L8S 4M1 Canada
}

\begin{abstract}
O} 1 \mathrm{~s}$ inner-shell excitation spectra of a number of vapor phase molecules containing peroxide bonds - hydrogen peroxide $\left(\mathrm{H}_{2} \mathrm{O}_{2}\right)$, di-t-butylperoxide ( $\left.{ }^{\mathrm{t}} \mathrm{BuO}{ }^{\mathrm{t}} \mathrm{Bu}\right)$, benzoyl peroxide, $\left(\left(\mathrm{C}_{6} \mathrm{H}_{5}(\mathrm{CO}) \mathrm{O}\right)_{2}\right)$, luperox-F [1,3(4)-bis(tertbutylperoxyisopropyl) benzene], and analogous, non-peroxide compounds water, t-butanol and benzoic acid have been measured. $\mathrm{C} 1 \mathrm{~s}$ spectra are also reported. $\mathrm{O}$ 1s spectra of solid benzoic acid, di-t-butylperoxide and luperox-F recorded using a scanning transmission X-ray microscope, are also reported, and compared to the corresponding gaseous spectra. Spectral interpretation was aided by comparing the spectra of the peroxide and non-peroxide counterparts and with ab initio calculations. A characteristic $\mathrm{O} 1 \mathrm{~s} \rightarrow \sigma^{*}{ }_{\mathrm{O}-\mathrm{O}}$ transition at 533.0(3) eV is identified in each peroxide species, which is absent in the corresponding non-peroxide counterpart species. The energy and intensity of the $533 \mathrm{eV}$ peroxide feature is stable and thus useful for analysis of peroxides in mixtures, such as tracking residual peroxide initiators, or peroxides produced in fuel cells.
\end{abstract}

Keywords: inner shell excitation, ISEELS, peroxides, STXM, C 1s, O 1s NEXAFS

File: peroxide-iseels-revised.doc Last changed: 03-Sep-2015

Chem. Phys. (submitted 30-July-2015) 


\section{Introduction}

Inner-shell excitation of gases and solids can be studied either by electron beams, using inner shell electron energy loss spectroscopy (ISEELS) [1,2] or by X-rays, using Near Edge X-ray Absorption Fine Structure (NEXAFS) spectroscopy [3-5]. Over the past decade or so, inner-shell excitation spectroscopy has emerged as a high spatial resolution analytical technique, with high quality spectra now being recorded at the nanoscale (sub-10 nm), using NEXAFS X-ray microscopes [6-8], and at the single atom scale (sub-0.1 nm) using ISEELS in transmission electron microscopes [9-11]. When applied with spatial resolution, inner-shell excitation spectroscopy provides a useful tool for micro- and nano-scale analysis of many types of materials. For maximum analytical utility it is important to understand the links between chemical structure and the associated inner shell spectra, particularly for important functional groups. It is also useful to have a library of reference spectra of compounds of known structure [12] for fingerprint purposes. In order to improve the utility of reference spectra it is desirable to have detailed spectroscopic assignments based on comparisons of series of closely related chemical species, aided by the results of high-quality quantum chemical calculations of the inner shell spectra [13-15]. Here we report a systematic experimental and computational study of the inner shell spectra of a number of peroxide compounds, with a focus on determining the existence, energy and intensity of a characteristic $\mathrm{O} 1 \mathrm{~s} \rightarrow \sigma^{*} \mathrm{O}-\mathrm{O}$ transition, as a function of the local structure around the peroxide group. The spectra are interpreted through comparison to the results of GSCF3 ab initio calculations on selected molecules $[13,14]$.

Peroxides are important in biology [16, 17], and as chemical reagents used as initiators in radical polymerization reactions [18]. They are also an unwanted by-product of catalytic oxygen reduction reactions in polymer electrolyte fuel cells [19-21]. Thus a possible application of inner shell excitation spectroscopy is in identifying and monitoring peroxide levels in various systems of biological or technological importance. The present study, which focuses on small molecules with the peroxy functional group, is intended to provide the fundamental spectroscopic background to such applications.

Prior studies of inner shell spectra of gas phase peroxides include studies by ISEELS of hydrogen peroxide and di-t-butyl peroxide in comparison to water and t-butanol [22], and of di-t-butyl peroxide in comparison to trifluoro methyl peroxide and other fluorinated species [23]. In those earlier studies, a peak at $533 \mathrm{eV}$ observed in the $\mathrm{O} 1 \mathrm{~s}$ spectra of each of the peroxide species was attributed to $\mathrm{O} 1 \mathrm{~s} \rightarrow \sigma^{*} \mathrm{O}-\mathrm{O}$ transitions. However, the role of this signal as a characteristic signature of the peroxide bond was not emphasized, and calculations were not done to confirm the assignment, aside from a theoretical study of the O 1s $\rightarrow$ LUMO (lowest unoccupied molecular orbital) transition of hydrogen peroxide [24]. To our 
knowledge this is the first report of the inner shell spectra of benzoyl peroxide $\left(\mathrm{C}_{6} \mathrm{H}_{5}(\mathrm{CO}) \mathrm{O}\right)_{2}$ and [1,3(4)-bis(tertbutylperoxyisopropyl) benzene]. These spectra were recorded in both the gas and solid phases. The $\mathrm{C}$ 1s NEXAFS spectrum of benzoic acid and some substituted benzoic acids have been reported by Baldea et al. [25] and interpreted with the aid of ab initio calculations. The structures of the molecules studied in this work are presented in scheme $\mathbf{1 .}$

\section{Experimental}

\subsection{Materials}

All compounds - di-t-butylperoxide ( ${ }^{\mathrm{t}} \mathrm{BuO}{ }^{\mathrm{t}} \mathrm{Bu}$ ) (Pfaltz\&Bauer, 98\%), benzoyl peroxide (Sigma Aldrich, 97\%) (BP) , [1,3(4) -bis(tertbutylperoxyisopropyl) benzene] (LF) (Arkema Inc., 97\%), water (Sigma Aldrich 99.9\%), and t-butanol (Sigma Aldrich >99\%) - were obtained commercially. Vapor phase hydrogen peroxide $\left(\mathrm{H}_{2} \mathrm{O}_{2}, 30 \%\right.$ aqueous solution, Sigma Aldrich) and phenol (Sigma Aldrich, $>89 \%$ ) were obtained by sampling the vapor above aqueous solutions through a leak valve. All species were used without further purification, although introducing the sample into the ISEELS gas cell through continuous flow was effectively purification by distillation. As evidence for this, often there were spurious signals from volatile impurities in the early period of the measurement. The spectra presented in this work were recorded only after the spectral shape had fully stabilized.

\subsection{Gas phase measurements by ISEELS}

The ISEELS apparatus and operating procedures have been described in detail elsewhere [1]. The instrument was operated in constant final energy mode with a final electron energy of $2.5 \mathrm{keV}$ so that the spectra are dominated by electric dipole transitions and thus are very close to the corresponding near edge X-ray absorption (NEXAFS) spectra. The energy resolution for most measurements was $0.7 \mathrm{eV}$ fwhm (full width at half maximum). The structured regions at the onset of inner shell excitation were recorded at higher resolution $(\sim 0.55 \mathrm{eV}$ fwhm) by reducing the gun current to $\sim 4 \mu \mathrm{A}$, to reduce resolution degradation associated with the Boersch (space charge) effect [26]. The gas phase spectra of most materials were obtained by placing $\sim 0.1 \mathrm{~g}$ in a metal tube directly attached to the collision cell. Benzoyl peroxide and benzoic acid required gentle heating to achieve adequate vapor density. The energy scale was calibrated by recording simultaneously the spectrum of the unknown and that of $\mathrm{CO}$ [27], $\mathrm{CO}_{2}$ [17, 28] or $\mathrm{O}_{2}[27]$. 


\subsection{Solid state measurements by STXM}

The $\mathrm{C}$ 1s and $\mathrm{O} 1 \mathrm{~s} \mathrm{X}$-ray absorption spectra of solid di-t-butylperoxide ( $\left.{ }^{\mathrm{t}} \mathrm{BuO}{ }^{\mathrm{t}} \mathrm{Bu}\right)$, benzoyl peroxide (BP) and [1,3(4)-bis(tertbutylperoxyisopropyl) benzene] ( $\mathbf{L F}$ ) were measured using transmission detection in a scanning transmission X-ray microscope (STXM) [29, 30] at either the Advanced Light Source (beamline 5.3.2.2, ALS, Berkeley, CA) or at the Canadian Light Source (ambient-STXM on the SM beamline, CLS, Saskatoon, SK). Samples were deposited on silicon nitride membranes and the microscope was used to find a small particle with peak optical density (OD) below 2 OD units, so that the spectra would not be distorted by absorption saturation. The energy scale was calibrated using the sharp Rydberg transitions of $\mathrm{CO}_{2}$ [31]. Transmission spectra through the particle were converted to absorption spectra using the Io spectrum recorded off the particle.

\subsection{Ab initio calculations}

To aid spectral assignment, $a b$ initio calculations of the $\mathrm{C} 1 \mathrm{~s}$ and $\mathrm{O} 1 \mathrm{~s}$ core excitation transitions were carried out using the GSCF3 package $[32,33]$. Significant alterations in the electronic structure due to relaxation in core excited states made these high level, explicit core hole calculations necessary in order to reliably reproduce inner shell spectra. These Hartree-Fock level calculations are based on the

improved virtual orbital approximation (IVO). They explicitly account for the effect of the core hole [34] and are highly optimised for calculating core excited states. A separate calculation was performed for each chemically distinct core excited atom. The difference in the total energy between the core ionized and ground state energies gave the core ionization potential (IP) with a typical accuracy of $\approx 2 \mathrm{eV}$ at the $\mathrm{C}$ 1s edge and $\approx 4 \mathrm{eV}$ at the $\mathrm{O}$ 1s edge (invariably at higher energy than the measured IP). However, the term values (TV) of the core states (TV = IP - E) obtained in the IVO approximation were relatively independent of the size of the basis set, and were accurate at the few tenths of an $\mathrm{eV}$ level.

Molecular geometries for molecules other than dibenzoyl peroxide were generated by ab initio geometry optimization at the 4-21G level using the GAMESS program [35]. For dibenzoyl peroxide, geometry optimization was performed at the 6-31G* level using the Spartan program. Identical basis sets were used for all ab initio calculations (Huzinaga Gaussian basis sets of 41121/2111/* on the core excitation site; 53/4 on heavy atoms, 6 on $\mathrm{H}$ ).

\section{Results and Discussion}

\subsection{O 1s spectra}


Figure 1 presents the $\mathrm{O}$ 1s electron energy loss spectra of 4 different peroxides - hydrogen peroxide [22], t-butyl peroxide [22,23], benzoyl peroxide (BP) and [1,3(4)-bis(tertbutylperoxyisopropyl) benzene] (LF) - recorded with dipole regime electron energy loss spectroscopy, background subtracted and converted to an intensity scale corresponding to the optical oscillator strength of two $\mathrm{O}$ atoms. In addition to the $\mathrm{O} 1 \mathrm{~s}$ spectra of the 4 peroxide species, Fig. 1 plots the spectrum of benzoic acid (BA), along with the difference of the spectra of benzoic acid and benzoyl peroxide, in order to isolate the contribution from the O-O peroxide in benzoyl peroxide. Table 1 reports the energies and estimated term values for selected features in the experimental $\mathrm{O} 1 \mathrm{~s}$ spectra of these molecules.

A vertical line at $533.0 \mathrm{eV}$ (see Fig. 1) passes through a strong, relatively broad transition in each peroxide species. his peak In the spectrum of benzoyl peroxide this peak is masked by strong transitions from the ester oxygen. The interference was removed by subtracting the spectrum of benzoic acid. The $533 \mathrm{eV} \sigma^{*}$ O-o feature is absent in water [22,36], the corresponding alcohol species, and benzoic acid, in each case the analogous molecules where there is no peroxide bond. This is the primary experimental evidence that the $533 \mathrm{eV}$ transition is a feature characteristic of the $\mathrm{O}-\mathrm{O}$ bond and thus one which can be used as an analytical fingerprint for peroxides. The $533 \mathrm{eV}$ peak in hydrogen peroxide has been identified previously as an $\mathrm{O} 1 \mathrm{~s} \rightarrow \sigma^{*} \mathrm{O}-\mathrm{O}$ transition [22]. This assignment is supported by ab initio calculations and by the detailed discussion of the spectrum of each species that follows.

Figure 2 presents the $\mathrm{O} 1 \mathrm{~s}$ spectrum of hydrogen peroxide [22] in comparison to the results of a GSCF3 calculation of $\mathrm{H}_{2} \mathrm{O}_{2}$. The inset plot of the LUMO clearly shows its $\sigma^{*}$ o-o character. The computed $\mathrm{O} 1 \mathrm{~s} \rightarrow$ LUMO state corresponds to the broad intense lowest energy peak, observed experimentally at $533.0 \mathrm{eV}$. The calculated position is $537.1 \mathrm{eV}$, about $4 \mathrm{eV}$ higher than the observed energy. Increasing the size of the basis set has essentially no influence on the predicted energy or degree of spatial localization. A shift of several $\mathrm{eV}$ to higher energy in the calculated relative to the experimental energy is typical of GSCF3 O 1s calculations, as well as other improved virtual orbital types of core excitation calculations [15]. The sharp features observed in the experimental spectrum between 534 and $540 \mathrm{eV}$ are most likely Rydberg states, which are not generally reproduced by GSCF3 with the approach we are using. The calculation does predict a relatively intense second peak at $540 \mathrm{eV}$ which should be seen at $536 \mathrm{eV}$, if the shift is similar to that found for the $\sigma^{*}{ }_{\mathrm{O}-\mathrm{O}}$ transition, and this is in reasonable agreement with the second peak in the experimental spectrum at $535.3 \mathrm{eV}$. The calculation also predicts a set of 3 transitions forming a broad band around $548 \mathrm{eV}$ (on the shifted energy scale). Experimentally, there is a broad maximum at $548 \mathrm{eV}$ to which the calculated feature may be related. 
Figure 3 presents the experimental [22] and GSCF3 calculated O 1s spectrum of t-butyl peroxide in comparison to the experimental and calculated spectra of t-BuOH [28]. The inset plot of the LUMO for t-butyl peroxide shows clearly its $\sigma^{*}$ o-o character. That feature is absent in the calculated $\mathrm{O} 1 \mathrm{~s}$ spectrum of $\mathrm{t}-\mathrm{BuOH}$. There is a low lying peak in the experimental $\mathrm{O} 1 \mathrm{~s}$ spectrum of $\mathrm{t}-\mathrm{BuOH}$ but it occurs at somewhat higher energy, and it is sharp and much lower intensity (evaluated as peak area) than the peroxide $\sigma^{*}$ o-o peak when compared to the $\mathrm{O} 1 \mathrm{~s}$ continuum intensity. The low lying feature in t-BuOH is attributed to $\mathrm{O} 1 \mathrm{~s}$ excitations to a mixed valence-Rydberg $\sigma^{*} \mathrm{O}=\mathrm{H} / 3 \mathrm{~s}$ orbital [28].

Figure 4a presents the $\mathrm{O} 1 \mathrm{~s}$ spectrum of benzoyl peroxide (BP) in comparison to the results of a GSCF3 calculation for the two symmetry inequivalent $\mathrm{O}$ atoms, along with their sum. The difference spectrum of BP minus BA for the gas phase data is also included to more clearly show the $533 \mathrm{eV}$ transition. Fig. $4 \mathrm{~b}$ presents a plot of the LUMO of O 1s excited benzoyl peroxide which shows clearly the $\sigma^{*}{ }_{\text {o-o }}$ character of the peak at $535.9 \mathrm{eV}$ in the calculated spectrum. This peak contributes to the broad signal centered around $533.8 \mathrm{eV}$ in the experimental spectrum, and is isolated in the BP - BA difference spectrum at $533.4 \mathrm{eV}$. The $\pi^{*} \mathrm{C}=\mathrm{O}$ peak occurs at $532 \mathrm{eV}$ in the calculated spectrum, and at $531.6 \mathrm{eV}$ in the experimental spectrum. The sharp peak at $538.9 \mathrm{eV}$ and the shallow maximum at $541.9 \mathrm{eV}$ in the calculated spectrum could together contribute to the hump at $540.5 \mathrm{eV}$ in the gas spectrum, while the broad transition computed to occur around $552 \mathrm{eV}$ does not have a counterpart in the experimental spectrum, and is most likely a computational artifact.

Figure 5 presents the $\mathrm{O}$ 1s spectrum of gas phase $\mathbf{L F}$ in comparison with that of solid $\mathbf{L F}$ and the results of a GSCF3 calculation for the two symmetry inequivalent $\mathrm{O}$ atoms, along with their sum. Here the discrete components of the spectrum are in good agreement with the experimental spectrum, although the strong peak predicted at $\sim 552 \mathrm{eV}$ (after correction for the estimated energy scale error) in the $\mathrm{O} 1 \mathrm{~s}$ continuum is not found in the experimental data. The inset plots show that the LUMO has a strong $\sigma^{*}$ o-o character at the two chemically inequivalent oxygen atoms of the peroxide group, but there is also some admixing with $\sigma^{*} \mathrm{C}=\mathrm{C}$ character on the phenyl ring.

The calculated energies of selected transitions in the $\mathrm{O} 1 \mathrm{~s}$ spectra of hydrogen peroxide, $\mathrm{t}-\mathrm{Bu}$ peroxide, benzoic acid, benzoyl peroxide and $\mathbf{L F}$ are summarized in table 2. The calculated energy of the $\mathrm{O} 1 \mathrm{~s} \rightarrow \sigma^{*} \mathrm{O}=\mathrm{O}$ transition is reasonably stable through the series, consistent with the experimental results. The average experimental $\mathrm{O} 1 \mathrm{~s} \rightarrow \sigma^{*} \mathrm{O}-\mathrm{O}$ transition energy is 533.0 (3) $\mathrm{eV}$ while the average calculated $\mathrm{O} 1 \mathrm{~s} \rightarrow \sigma^{*} \mathrm{O}$-o transition energy is $537.0(6) \mathrm{eV}$. The relative independence of the transition energy to the structure of the remainder of the molecule (both in experiment and calculation) indicates 
there is relatively little electronic interaction between the non-peroxide and peroxide parts of these molecules.

\subsection{1s spectra}

Figure 6 presents the C 1s spectra of t-butanol [28], t-butyl peroxide [22], benzoic acid, benzoyl peroxide and [1,3(4)-bis(tertbutylperoxyisopropyl) benzene] (LF). In this case the intensity scale is absolute on a per carbon basis. The shapes of the spectra of the common functional groups - t-butyl, or benzoyl - are in very good agreement, further stressing the point that there is little interaction between the peroxide group and the organic substituents. The spectra of the t-butyl species are dominated by a broad transition at $294 \mathrm{eV}$, corresponding to overlapping $\mathrm{C} 1 \mathrm{~s} \rightarrow \sigma^{*}{ }_{\mathrm{C}-\mathrm{C}}$ and $\mathrm{C} 1 \mathrm{~s} \rightarrow \sigma^{*}{ }_{\mathrm{C}-\mathrm{O}}$ transitions while the sharp features at $288 \mathrm{eV}$ correspond to $\mathrm{C} 1 \mathrm{~s} \rightarrow \sigma^{*}{ }_{\mathrm{C}-\mathrm{H}}$ transitions. The $\mathrm{C} 1 \mathrm{~s}$ spectra of the two benzoyl species are dominated by the $\mathrm{C} 1 \mathrm{~s}(\mathrm{C}=\mathrm{C}) \rightarrow \pi^{*}{ }_{\mathrm{C}=\mathrm{C}}$ transition at $285 \mathrm{eV}$ and the $\mathrm{C} 1 \mathrm{~s}(\mathrm{C}=\mathrm{O}) \rightarrow$ $\pi^{*} \mathrm{C}=\mathrm{O}$ transition at $288 \mathrm{eV}$, while the higher energy broad transitions at $\sim 293,298$ and $\sim 304 \mathrm{eV}$ are characteristic of $\mathrm{C} 1 \mathrm{~s}(\mathrm{C}=\mathrm{C}) \rightarrow \sigma^{*}$ transitions of the phenyl ring.

Figure 7 presents the $\mathrm{C}$ 1s spectrum of benzoic acid, in comparison to the results of a GSCF3 calculation for the five symmetry inequivalent $\mathrm{C}$ atom sites, along with their weighted sum. The experimental spectrum is in good agreement with that reported by Baldea et al. [25]. The sharp transition at $285.1 \mathrm{eV}$ is of phenyl ring $\pi^{*}$ character. The corresponding peak in the calculated spectrum has an energy of $287.6 \mathrm{eV}, 2.5 \mathrm{eV}$ higher than observed. This discrepancy is typical of GSCF3 calculations, as they usually overestimate $\mathrm{C} 1 \mathrm{~s}$ energies by about $2-3 \mathrm{eV}$ [37]. The second sharp peak at $288.3 \mathrm{eV}$ corresponds to the $\pi^{*} \mathrm{C}=\mathrm{O}$ transition; the corresponding peak in the calculated spectra occurs at $291.0 \mathrm{eV}$. The plot of the upper orbital of this transition shows some delocalization towards the peroxide oxygen. There is also a broad band from 290 to $310 \mathrm{eV}$ in the experimental spectrum, in which there are three discernible maxima located at 293.2, 299.5 and $303.2 \mathrm{eV}$. The C 1s spectra of benzoic acid [38] and aminobenzoic acid [39] adsorbed to $\mathrm{TiO}_{2}(110)$ both exhibit the two strong features seen in the gas phase spectrum of benzoic acid at the same energies.

Figure 8 presents the $\mathrm{C}$ 1s spectrum of benzoyl peroxide (gas and solid) in comparison to the results of a GSCF3 calculation for the seven symmetry inequivalent $\mathrm{C}$ atom sites, along with their weighted sum. As expected, the spectrum shows strong similarities to that of benzoic acid (Fig. 7). The sharp peak at $285.0 \mathrm{eV}$ is of phenyl ring $\pi^{*}$ character. The corresponding peak in the calculated spectra occurs at $287.6 \mathrm{eV}$, approximately $2.6 \mathrm{eV}$ higher than observed. The second sharp peak at $288.2 \mathrm{eV}$ corresponding to the $\pi{ }^{*} \mathrm{C}=\mathrm{O}$ transition; the corresponding peak in the calculated spectra occurs at 291.4 
$\mathrm{eV}$. The similarity between the $\mathrm{C} 1 \mathrm{~s}$ spectra of benzoyl peroxide and benzoic acid indicates that $\sigma^{*} \mathrm{o}$-o bonding character is very localized and does not have an effect on the electronic structure of the nonperoxide moiety. This localized effect is also observed in the $\mathrm{O} 1 \mathrm{~s}$ spectra of the peroxides.

\section{Discussion}

The independence of the $\mathrm{O} 1 \mathrm{~s} \rightarrow \sigma^{*} \mathrm{O}=\mathrm{O}$ transition from the surroundings of the peroxide group is most likely related to the fact that the upper level is localized at the $\mathrm{O}-\mathrm{O}$ bond, and has limited electronic interaction with neighboring functional groups. Based on the known dependence of $1 \mathrm{~s} \rightarrow \sigma^{*} \mathrm{~A}-\mathrm{B}$ transition energies on the A-B bond length [40-42], there should be some dependence of the transition energy on the $\mathrm{O}-\mathrm{O}$ bond length but the range of O-O bond lengths is relatively small, 143-149 pm [43] in all of the peroxides we have examined. Figure 9 plots predicted $\mathrm{O} 1 \mathrm{~s}$ spectra of hydrogen peroxide for artificial structures with O-O bond lengths ranging from 137 to $157 \mathrm{pm}$. As found in earlier experimental [40] and theoretical $[41,42]$ work, the position of $\mathrm{X} 1 \mathrm{~s} \rightarrow \sigma^{*} \mathrm{X}$-Y transitions varies systematically with the X-Y bond length, when the data is grouped such that the sum of the atomic numbers of $\mathrm{X}$ and $\mathrm{Y}$ are the same. The GSCF3 calculations predict a slope of the term value for the $\mathrm{X} 1 \mathrm{~s} \rightarrow \sigma^{*} \mathrm{X}-\mathrm{Y}$ transition versus bond length of $0.25 \mathrm{eV} / \mathrm{pm}$, in good agreement with the slope of $0.30 \mathrm{eV} / \mathrm{pm}$ determined for other $\mathrm{Z}=16$ systems (N-F, O-O) [40]. Note that the energies of higher energy transitions in the same spectra are very much less sensitive to the change in the O-O bond length, supporting the idea that the final orbital of the $\mathrm{O} 1 \mathrm{~s} \rightarrow \sigma^{*} \mathrm{O}-\mathrm{o}$ transition is very localized between the two $\mathrm{O}$ atoms. Thus the constancy of the position of the $\mathrm{O} 1 \mathrm{~s} \rightarrow \sigma^{*} \mathrm{O}-\mathrm{O}$ transition is the related to the lack of electronic interaction with its surroundings resulting in a nearly constant $\mathrm{O}-\mathrm{O}$ bond length. The computed behavior with bond length is a strong indication that the $\mathrm{O} 1 \mathrm{~s} \rightarrow \sigma^{*} \mathrm{O}$-o transition in peroxides has shape resonance character.

What is the significance of this work? Peroxides are found in both natural biological systems (e.g. plant defenses against insects [44]), products of cellular NADPH oxidases [45], indicators of oxidative stress in humans [46]) and technological systems (radical polymerization catalysts [18, 43], hydrogen fuel cells [19-21]) etc. The ability to identify and quantify the peroxide functional group through core excitation spectroscopy could be useful in such situations, although there are also issues with respect to interference from the $\mathrm{O} 1 \mathrm{~s}$ spectra of other oxygenated species in some systems (as exemplified by the case of benzoyl peroxide). We note that the $533 \mathrm{eV} \sigma^{*}$ o-o transition lies below the onset of the $\mathrm{O} 1 \mathrm{~s}$ absorption of water and substantially above that of the strong $532.1 \mathrm{eV}$ amide peak in proteins. This analytical functionality may be especially useful when implemented with spatial resolution, as in STXM 
or TEM-EELS, where one could spatially map peroxides; or when implemented with time resolution and correlation with changing reaction conditions, as in operando spectroscopy or spectromicroscopy.

Because of the ubiquity of peroxides, numerous methods of detecting these species - especially hydrogen peroxide - have been developed. Of these, electrochemical methods have found the widest use [47]. Detecting hydrogen peroxide using electrodes coated with an electrocatalyst such as Prussian Blue is relatively cheap, selective and sensitive, with detection limits of $0.1 \mu \mathrm{M}$ reported [48]. Nonetheless, core excitation spectroscopy could offer advantages even relative to this traditional and well developed method. The signature peroxide peak at $533 \mathrm{eV}$ allows core excitation spectroscopy to be used to detect any compound containing the peroxide functional group, whereas electrochemical methods are usually specific to one peroxide of interest, typically hydrogen peroxide. Detecting other peroxides electrochemically requires experimental changes and may not be as accurate. It is also challenging to implement electrochemical methods with spatial resolution. On the other hand, core excitation spectroscopy can detect all peroxides in a system in a single experiment without the need for equipment specialized to only one compound. In systems in which many types of peroxides may be present and are of interest, such as in the oxidative degradation of polymers like polypropylene into hydrogen peroxide and other peroxides [49], using this method to detect and quantify all peroxide species could be beneficial. In addition methods such as X-ray and electron spectromicroscopies allow application of peroxide analysis with fine spatial resolution.

\section{Summary}

The $\mathrm{O} 1 \mathrm{~s}$ and $\mathrm{C} 1 \mathrm{~s}$ spectra of a number of gas phase compounds containing peroxide bonds have been measured and compared to closely related species which do not contain a peroxide bond. The experimental spectra, supported by the results of $a b$ initio calculations, indicate that an intense, relatively broad peak at 533.0(3) eV is characteristic of the presence of a peroxide bond, irrespective of the overall structure of the molecule. This $\mathrm{O} 1 \mathrm{~s} \rightarrow \sigma^{*} \mathrm{O}=\mathrm{O}$ transition can act as a 'signature' for the presence of a peroxide bond and be used in analytical applications.

\section{Acknowledgements}

This research was supported by NSERC and by a grant from Imperial Oil. Spectra of the solid species were measured using STXMs at the Advanced Light Source, which is supported by Basic Energy Sciences (DoE, USA), and at the Canadian Light Source (Saskatoon) which is supported by CFI, NSERC, CIHR, NRC and the University of Saskatchewan.. We thank David Kilcoyne and Tolek Tyliszczak (ALS) for their excellent support of STXM 5.3.2.2 and Chithra Karunakaran and Jian Wang 
for their support of the CLS ambient STXM on beam line 10ID1.

\section{References}

1. A.P. Hitchcock, Physica Scripta T31 (1990) 159

2. A.P. Hitchcock and D.C. Mancini, J. Electron Spectrosc. Relat. Phenom. 67 (1994) 1

3. J. Stöhr, NEXAFS Spectroscopy, Springer-Verlag, Berlin (1992)

4. J. Kikuma and B. Tonner, J. Electron Spectrosc. Relat. Phenom 62 (1996) 53

5. H. Ade and S.G. Urquhart, NEXAFS Spectroscopy and Microscopy of Natural and Synthetic Polymers in Chemical Applications of Synchrotron Radiation, T. K. Sham, Eds., (World Scientific Publishing, Singapore, 2002) 285.

6. M. Howells, C. Jacobsen and T. Warwick, Principles And Applications of Zone Plate X-Ray Microscopes in Science of Microscopy, Peter W. Hawkes and John C. H. Spence, eds, (Springer, NY, 2007)

7. H. Ade and A.P. Hitchcock, Polymer 49 (2008) 643.

8. D.A. Shapiro, Y.-S. Yu, T. Tyliszczak, J. Cabana, R. Celestre, W. Chao, K. Kaznatcheev, A. L. D. Kilcoyne, F. Maia, S. Marchesini, Y. S. Meng, T. Warwick, L. L.Yang and H.A. Padmore, Nature Photonics $\underline{8}$, (2014) 765-769

9. L.C. Sawyer and D.T. Grubb, Polymer Microscopy (Chapman and Hall, NY, 1987)

10. R. F. Egerton, Electron Energy Loss Spectroscopy in the Electron Microscope, Plenum Press, New York (1996).

11. G.A. Botton, S. Lazar and C. Dwyer. Ultramicroscopy, 110 (2010) 926-934.

12. A.P. Hitchcock, Core Excitation Database, http://unicorn.mcmaster.ca/corex/cedb-title.html

13. N. Kosugi and H. Kuroda, Chemical Physics Letters, 74, (1980) 490

14. N. Kosugi, Theor. Chim. Acta, 72, (1987) 149.

15. L. Triguero, L. G. M. Pettersson and H. Agren, Physical Review B $\underline{58}$ (1998) 8097.

16. M. Jung, H. Kim, K. Lee and M. Park, Mini Rev. Med. Chem. 3 (2003) 159-65.

17. M. Giorgio, M. Trinei, E. Migliaccio and P.G. Pelicci, Nature Reviews Molecular Cell Biology $\underline{8}$ (2007) $722-728$

18. D. Braun, Review Article Origins and Development of Initiation of Free Radical Polymerization Processes Int. J. Polymer Science (2009) 893234 - (1-10)

19. L. An, T. Zhou, X. Yan, X. Zhou and P. Tan, Science Bulletin 60 (2015) 55-64.

20. W. Lie and D. Zuckerbrod, J. Electrochem. Soc. 152 (2005) A1165-A1170

21. N. Ramaswamy, N. Hakim amd S. Mukerjee, Electrochimica Acta 53 (2008) 3279-3295

22. E. Rühl and A.P. Hitchcock, Chem. Phys. 154 (1991) 323

23. I. Ishii, R. McLaren, A.P. Hitchcock and M.B. Robin, J. Chem. Phys. $\underline{87}$ (1987) 4344

24. J.A. Tossell and D.J. Vaughan, J. Col. Int. Sci. 155 (1993) 98. 
25. I. Baldea, B. Schimmelpfennig, M. Plaschke, J. Rothe, J.Schirmer, A.B. Trofimov and Th. Fanghd'el, J. Electron Spectrosc. Relat. Phenom., 154 (2007) 109.

26. G.H. Jansen, J. Vac. Sci. Tech. B $\underline{6}$ (1988) 1977.

27. R. N. S. Sodhi and C. E. Brion, J. Electron Spectrosc. Relat. Phenom., 34, (1984) 363.

28. I. Ishii and A.P. Hitchcock, J. Electron Spectrosc. Relat. Phenom. 46 (1987) 55.

29. A.L.D. Kilcoyne, T. Tylisczak, W.F. Steele, S. Fakra, P. Hitchcock, K. Franck, E. Anderson, B. Harteneck, E.G. Rightor, G.E. Mitchell, A. P. Hitchcock, L. Yang, T. Warwick, H. Ade, J. Synchrotron Radiation $\underline{10}$ (2003) 125-136.

30. A.P. Hitchcock, Soft X-ray Imaging and Spectromicroscopy Chapter 22 in Volume II of the Handbook on Nanoscopy, eds. Gustaaf Van Tendeloo, Dirk Van Dyck and Stephen J. Pennycook (Wiley, 2012) pp 745-791

31. Y. Ma, C. T. Chen, G. Meigs, K. Randall, and F. Sette, Phys. Rev. A 44 (2091) 1848

32. N. Kosugi, E. Shigemasa and A. Yagishita, Chem Phys. Lett., 190 (1992) 481.

33. N. Kosugi, J. Adachi, E. Shigemasa and A. Yagishita, J. Chem. Phys., 97 (1992) 8842.

34. W. J. Hunt and W.A.I. Goddard, Chemical Physics Letters, $\underline{3}$ (1969) 414.

35. M. W. Schmidt, K. K. Baldridge, J. A. Boatz, S. T. Elbert, M. S. Gordon, J. J. Jensen, S. Koseki, N. Matsunaga, K. A. Nguyen, S. Su, T. L. Windus, M. Dupuis and J. A. Montgomery, J. Computational Chemistry, 14, (1993) 1347.

36. J. Schirmer, A.B. Trofimov, K.J. Randall, J. Feldhaus, A.M. Bradshaw, Y. Ma, C.T. Chen and F. Sette, Phys. Rev. A $\underline{47}$ (1993) 1136.

37. C.C. Turci, S.G. Urquhart and A.P. Hitchcock, Can. J. Chem. 74 (1996) 851-869

38. J. Schnadt, J. N. O’Shea, L. Patthey, J. Krempaský, N. Mårtensson, and P. A. Brühwiler, Phys. Rev. B $\underline{67}$ (2003) 235420

39. A.G. Thomas, M. J. Jackman, M. Wagstaffe, H. Radtke, K.Syres, J. Adell, A. Lévy and N, Martsinovich , Langmuir $\underline{30}$ (2014) 12306-12314

40. F. Sette, J. Stöhr and A.P. Hitchcock, J. Chem. Phys. 81 (1984) 4906

41. J. A. Sheehy, T. J. Gil, C. L. Winstead, R. E. Farren and P. W. Langhoff, J. Chem. Phys. 91 (1989) 1796

42. V.L. Shneerson, D.K. Saldin and W.T. Tysoe, Surface Science 375 (1997) 340

43. E. T. Denisov, Taissa G. Denisova, T. S. Pokidova, Handbook of Free Radical Initiators (Wiley, 2003) Table 5.4

44. J. Fürstenberg-Hägg, M. Zagrobelny and S. Bak Int. J. Molecular Sciences. 14 (2013) 10242-10297

45. W.M. Nauseef, Biochim Biophys Acta. 1840 (2014) 757-67.

46. R.E. Rugo and R.H. Schiestl, Radiation Research 162 (2004) 416-425

47. Z. Wu, Z. Chen, T. Zhang, T. Guo, Z. Wang, and F. Liao, Electrochimica Acta, 98 (2013), 104

48. M.A. Komkova, E.E Karyakina, F. Marken and A.A. Karyakin, Anal Chem. 85 (2013) 2574-7.

49. C. Butler and P.M. Whitmore, Polym. Degrad. Stabil., $\underline{98}$ (2013) 471. 
Table 1 Experimental energies, estimated term values and proposed assignments for selected features in the $\mathrm{O}$ 1s spectra of hydrogen peroxide [22] t-Bu peroxide [23], luperox-F (LF), and benzoyl peroxide (BP)

\begin{tabular}{|c|c|c|c|c|c|c|c|c|}
\hline \multicolumn{2}{|c|}{$\begin{array}{c}\text { HOOH } \\
\text { previously reported [22] }\end{array}$} & \multicolumn{2}{|c|}{ LF } & \multicolumn{2}{|c|}{$\begin{array}{c}\text { tBu-O-O-tBu } \\
\text { previously reported [23] }\end{array}$} & \multicolumn{2}{|c|}{ BP } & \multirow[b]{2}{*}{ Assignment } \\
\hline $\mathrm{E}$ & $\mathrm{TV}$ & $\mathrm{E}$ & TV & E & TV & $\mathrm{E}$ & TV & \\
\hline & & & & & & $531.6^{\mathrm{d}}$ & & $\pi^{*}(\mathrm{C}=\mathrm{O})$ \\
\hline $533.0^{\mathrm{a}}$ & 8.8 & $533.0^{\mathrm{b}}$ & 8.5 & $533.0^{\mathrm{c}}$ & 8.5 & 533.8 & & $\sigma^{*}(\mathrm{O}-\mathrm{O})$ \\
\hline 535.3 & 6.8 & & & & & & & $\sigma^{*}(\mathrm{O}-\mathrm{H})$ \\
\hline \multirow[t]{2}{*}{536.8} & 5.0 & 536.4 & 5.10 & 536.5 & 5.0 & & & $3 \mathrm{~s}$ \\
\hline & & 537.4 & 4.10 & 538.2 & 3.3 & & & $\sigma^{*}(\mathrm{O}-\mathrm{C})$ \\
\hline
\end{tabular}

Calibration

a. $\mathrm{HOOH}$ : gas: $2.42(7) \mathrm{eV}$ relative to $\pi *$ transition in $\mathrm{O}_{2}(530.8(1))[27]$

b. LF: gas : 2.19(6) eV relative to $\pi^{*}$ transition in $\mathrm{O}_{2}(530.8(1))$ [27]

solid: - calibrated from Rydberg transitions of $\mathrm{CO}_{2}$ [31]

c. $\mathrm{tBu}-\mathrm{O}-\mathrm{O}-\mathrm{tBu}(245.24 \mathrm{eV}$ above first feature in $\mathrm{C} 1 \mathrm{~s}$ spectrum [28])

d) BP: gas: $-3.75(5) \mathrm{eV}$ relative to $\pi^{*}$ transition in $\mathrm{CO}_{2}(535.4(1))$ [27]

solid - calibrated from Rydberg transitions of $\mathrm{CO}_{2}[31]$ 
Table 2 Results of GSCF3 calculations ${ }^{(\mathrm{a}, \mathrm{b})}$ of $\mathrm{O}$ 1s spectral transitions of hydrogen peroxide, t-Bu peroxide,benzoic acid, benzoyl peroxide and $\mathbf{L F}$

\begin{tabular}{|c|c|c|c|c|}
\hline Site & IP & Assignment & $\varepsilon(\mathrm{eV})$ & $f\left(10^{-2}\right)$ \\
\hline \multicolumn{5}{|l|}{ НОOH } \\
\hline \multirow[t]{3}{*}{$\mathrm{O}$} & 540.475 & $\sigma^{*}(\mathrm{O}-\mathrm{O})$ & -3.302 & 3.1 \\
\hline & & $\sigma^{*}(\mathrm{O}-\mathrm{H})$ & -0.371 & 0.96 \\
\hline & & $\sigma^{*}(\mathrm{O}-\mathrm{H})$ & 2.163 & 0.12 \\
\hline \multicolumn{5}{|c|}{ t-Butyl Peroxide } \\
\hline \multirow[t]{2}{*}{$\mathrm{O}$} & 539.124 & $\sigma^{*}(\mathrm{O}-\mathrm{O})$ & -2.694 & 2.67 \\
\hline & & $\sigma^{*}(\mathrm{O}-\mathrm{C})$ & 1.538 & 0.75 \\
\hline \multicolumn{5}{|c|}{ Benzoic Acid } \\
\hline \multirow[t]{3}{*}{$\mathrm{O} 1$} & 540.406 & $\pi^{*}(\mathrm{O}-\mathrm{C})$ & -5.002 & 0.28 \\
\hline & & $\sigma^{*}(\mathrm{O}-\mathrm{H})$ & -0.916 & 0.80 \\
\hline & & $\sigma^{*}(\mathrm{O}-\mathrm{C})$ & 2.293 & 0.23 \\
\hline \multirow[t]{2}{*}{$\mathrm{O} 2$} & 538.272 & $\pi^{*}(\mathrm{O}=\mathrm{C})$ & -6.247 & 1.09 \\
\hline & & $\begin{array}{c}\pi^{*}(\mathrm{O}=\mathrm{C}, \text { del. } \\
\text { ring })\end{array}$ & -1.532 & 0.17 \\
\hline \multicolumn{5}{|c|}{ Benzoyl Peroxide } \\
\hline \multirow[t]{4}{*}{$\mathrm{O} 1$} & 541.880 & $\sigma^{*}(\mathrm{O}-\mathrm{O})$ & -5.990 & 1.34 \\
\hline & & $\sigma^{*}(\mathrm{O}-\mathrm{O})$ & -3.035 & 0.67 \\
\hline & & $\pi^{*}(\mathrm{C}=\mathrm{O})$ & 0.099 & 0.13 \\
\hline & & $\sigma^{*}\left(\mathrm{O}-\mathrm{O} *-\mathrm{C}^{*}\right)$ & 4.812 & 0.11 \\
\hline \multirow[t]{3}{*}{$\mathrm{O} 2$} & 538.089 & $\pi^{*}(\mathrm{C}=\mathrm{O})$ & -6.177 & 0.93 \\
\hline & & $\pi^{*}$ (C-Ring) & -1.678 & 0.17 \\
\hline & & $\sigma^{*}(\mathrm{C}=\mathrm{O})$ & 4.284 & 0.33 \\
\hline \multicolumn{5}{|l|}{$\mathbf{L F}$} \\
\hline \multirow[t]{4}{*}{$\mathrm{O} 3$} & 539.282 & $\sigma^{*}(\mathrm{O}-\mathrm{O}) \mathrm{del}$ & -1.456 & 0.59 \\
\hline & & $\sigma^{*}(\mathrm{O}-\mathrm{O})$ & -1.053 & 0.54 \\
\hline & & $\sigma^{*}\left(\mathrm{O}-\mathrm{C}\left(\mathrm{CH}_{3}\right)_{3}\right)$ & 1.765 & 0.83 \\
\hline & & $\pi^{*}\left(\mathrm{O}-\mathrm{C}\left(\mathrm{CH}_{3}\right)_{3}\right)$ & 8.535 & 0.04 \\
\hline \multirow[t]{3}{*}{$\mathrm{O} 4$} & 539.368 & $\sigma^{*}(\mathrm{O}-\mathrm{O})$ & -1.507 & 0.15 \\
\hline & & $\sigma^{*}(\mathrm{O}-\mathrm{O})$ & -1.238 & 1.00 \\
\hline & & $\sigma^{*}(\mathrm{O}-\mathrm{Ph})$ & 2.047 & 0.36 \\
\hline
\end{tabular}

a. Geometries: All calculated at 4-21G level by GAMESS, except BP, calculated at the 6-31G* level by Spartan.

b. GSCF3 calculation basis set:

Core excited atom: 411121/2111/*

Heavy atoms: $\quad 521 / 31(53 / 4)$

Hydrogen: $\quad 51(6)$ 
Table 3 Experimental energies, estimated term values and proposed assignments for selected features in the C 1s spectra of t-Bu peroxide [22], LF, and benzoyl peroxide (BP)

\begin{tabular}{|c|c|c|c|c|c|c|c|}
\hline \multicolumn{2}{|c|}{ LuF } & \multicolumn{2}{c|}{ tBu-O-O-tBu } & \multicolumn{2}{c|}{ BP } & \\
\hline E & TV & E & TV & E & {$[25]$} & TV & Assignment \\
\hline $285.0(9)^{(\mathrm{a})}$ & IP Benzene? & & & $285.0^{(\mathrm{c})}$ & 284.9 & & $\pi^{*}$ Ring \\
\hline 288.6 & 1.9 & $287.9^{(\mathrm{b})}$ & 2.6 & 288.2 & 288.2 & & $\sigma^{*}(\mathrm{C}-\mathrm{H})$ \\
\hline & & & & 288.2 & 288.2 & & $\pi^{*}(\mathrm{C}=\mathrm{O})$ \\
\hline 291.2 & 1.3 & 291.3 & 1.2 & & & & $\sigma^{*}(\mathrm{C}-\mathrm{O})$ \\
\hline 293.3 & IP Benzene? & & & & & & $\sigma^{*}(\mathrm{Ph}-\mathrm{O})$ \\
\hline & & & & 296.5 & & & $3 \mathrm{p}$ \\
\hline
\end{tabular}

\section{Calibration}

a. LF: gas : -5.66(4) eV relative to $\pi *$ transition in $\mathrm{CO}_{2}(290.74(4))$ [27];

solid: - calibrated from Rydberg transitions of $\mathrm{CO}_{2}[31]$

b. ${ }^{\mathrm{t}} \mathrm{Bu}-\mathrm{O}-\mathrm{O}-{ }^{\mathrm{t}} \mathrm{Bu}: 287.9 \mathrm{eV}$, calibrated 2.80(7) eV below the $\mathrm{C} 1 \mathrm{~s} \rightarrow \pi^{*}$ transition in $\mathrm{CO}_{2}(290.74(4)$ [27])

c. BP: gas: $-5.73(7)$ eV relative to $\pi^{*}$ transition in $\mathrm{CO}_{2}$ (290.74(4)) [27];

solid: - calibrated from Rydberg transitions of $\mathrm{CO}_{2}$ [31] 
Table 4 Results of GSCF3 calculations ${ }^{(a, b)}$ of the C 1s spectral transitions of t-butyl peroxide, benzoic acid, benzoyl peroxide and $\mathbf{L F}$

\begin{tabular}{|c|c|c|c|c|}
\hline Site & IP & Assignment & $\varepsilon(\mathrm{eV})$ & $f\left(10^{-2}\right)$ \\
\hline \multicolumn{5}{|c|}{ tButyl Peroxide } \\
\hline \multirow[t]{3}{*}{$\mathrm{C} 2$} & 294.508 & $\sigma^{*}(\mathrm{C}-\mathrm{O}$, del. $)$ & -0.436 & 0.80 \\
\hline & & $\sigma^{*}(\mathrm{C}-\mathrm{C}$ del. $)$ & 1.457 & 1.00 \\
\hline & & $\sigma^{*}(\mathrm{C}-\mathrm{C})$ & 3.396 & 0.55 \\
\hline \multirow[t]{3}{*}{$\mathrm{C} 3$} & 291.714 & $\sigma^{*}(\mathrm{C}-\mathrm{H}$, del. $)$ & 1.535 & 0.43 \\
\hline & & $\sigma^{*}(\mathrm{C}-\mathrm{C})$ & 2.225 & 0.44 \\
\hline & & $\sigma^{*}(\mathrm{C}-\mathrm{H})$ & 3.178 & 0.45 \\
\hline \multicolumn{5}{|c|}{ Benzoic Acid } \\
\hline \multirow[t]{2}{*}{$\mathrm{C} 3$} & 297.742 & $\pi^{*}(\mathrm{O}-\mathrm{C}=\mathrm{O})$ & -6.734 & 6.25 \\
\hline & & $\pi^{*}($ Ring $-\mathrm{C}=\mathrm{O})$ & -2.092 & 2.50 \\
\hline \multirow[t]{3}{*}{$\mathrm{C} 4$} & 293.247 & $\pi^{*}($ Ring $-\mathrm{C}=\mathrm{O})$ & -5.727 & 2.20 \\
\hline & & $\pi^{*}(\mathrm{C}-\mathrm{CO} 2 \mathrm{H})$ & -1.111 & 0.32 \\
\hline & & $\pi^{*}$ (Ring) & 2.203 & 0.37 \\
\hline \multirow[t]{3}{*}{ C5 } & 292.791 & $\pi^{*}($ Ring $-\mathrm{C}=\mathrm{O})$ & -5.514 & 2.83 \\
\hline & & $\pi^{*}$ (Ring) & -4.142 & 0.39 \\
\hline & & $\sigma^{*}(\mathrm{C}-\mathrm{H})$ & 1.671 & 0.60 \\
\hline \multirow[t]{3}{*}{ C6 } & 292.722 & $\pi^{*}$ (Ring) & -5.087 & 2.70 \\
\hline & & $\pi^{*}($ Ring $-\mathrm{C}=\mathrm{O})$ & -4.254 & 0.34 \\
\hline & & $\sigma^{*}(\mathrm{C}-\mathrm{H})$ & 1.326 & 0.65 \\
\hline \multirow[t]{3}{*}{$\mathrm{C} 7$} & 292.796 & $\pi^{*}($ Ring $-\mathrm{C}=\mathrm{O})$ & -5.537 & 2.80 \\
\hline & & $\pi^{*}(\mathrm{C}-\mathrm{CO} 2 \mathrm{H})$ & -0.446 & 0.37 \\
\hline & & $\sigma^{*}(\mathrm{C}-\mathrm{H})$ & 1.340 & 0.66 \\
\hline \multicolumn{5}{|c|}{ Benzoyl Peroxide } \\
\hline \multirow[t]{2}{*}{$\mathrm{C} 3$} & 297.855 & $\pi^{*}(\mathrm{C}=\mathrm{O})$ & -6.55 & 4.69 \\
\hline & & $\pi^{*}$ & -1.298 & 1.56 \\
\hline \multirow[t]{3}{*}{$\mathrm{C} 4$} & 293.527 & $\pi *$ (Ring) & -5.742 & 1.91 \\
\hline & & $\pi^{*}\left(\mathrm{C}^{*}-\mathrm{C}=\mathrm{O}\right)$ & -1.162 & 0.40 \\
\hline & & $\pi^{*}($ Ring $)$ & 2.118 & 0.43 \\
\hline \multirow[t]{2}{*}{ C5 } & 292.978 & $\pi^{*}$ (Ring) & -5.518 & 2.46 \\
\hline & & $\pi^{*}$ (Ring, del.) & -4.165 & 0.31 \\
\hline \multirow[t]{2}{*}{ C6 } & 292.955 & $\pi^{*}$ (Ring) & -5.586 & 2.45 \\
\hline & & $\pi^{*}$ (Ring, del.) & -4.208 & 0.33 \\
\hline \multirow[t]{3}{*}{ C7 } & 292.855 & $\pi^{*}$ (Ring) & -5.165 & 2.36 \\
\hline & & $\pi^{*}$ (Ring, del.) & -4.359 & 0.27 \\
\hline & & $\sigma^{*}(\mathrm{C}-\mathrm{H})$ & 1.153 & 1.05 \\
\hline \multirow[t]{3}{*}{ C8 } & 292.850 & $\pi^{*}$ (Ring) & -5.169 & 2.36 \\
\hline & & $\pi^{*}$ (Ring, del.) & -4.362 & 0.27 \\
\hline & & $\sigma^{*}(\mathrm{C}-\mathrm{H})$ & 1.081 & 0.88 \\
\hline \multirow[t]{3}{*}{ C9 } & 292.923 & $\pi^{*}(\mathrm{Ring})$ & -5.622 & 2.42 \\
\hline & & $\pi^{*}$ (Ring, del.) & -0.558 & 0.53 \\
\hline & & $\sigma^{*}(\mathrm{C}-\mathrm{H})$ & 1.194 & 1.01 \\
\hline
\end{tabular}


Table 4 (continued)

\begin{tabular}{|c|c|c|c|c|}
\hline Site & IP & Assignment & $\varepsilon(\mathrm{eV})$ & $f\left(10^{-2}\right)$ \\
\hline \multirow[t]{3}{*}{$\mathrm{C} 1$} & 291.737 & $?$ & 1.868 & 0.66 \\
\hline & & $\sigma^{*}(\mathrm{C}-\mathrm{H})$ & 2.168 & 0.24 \\
\hline & & $\sigma^{*}(\mathrm{C}-\mathrm{H})$ & 2.454 & 0.58 \\
\hline \multirow[t]{4}{*}{$\mathrm{C} 2$} & 294.517 & $\sigma^{*}(\mathrm{C}-\mathrm{O})$ & 0.396 & 1.19 \\
\hline & & $\sigma^{*}(\mathrm{C}-\mathrm{C}) ?$ & 2.029 & 0.36 \\
\hline & & $?$ & 3.202 & 0.64 \\
\hline & & $\sigma^{*}(\mathrm{C}-\mathrm{C}) ?$ & 3.439 & 0.48 \\
\hline \multirow[t]{4}{*}{ C5 } & 294.559 & $\pi^{*}$ (Ring) & -2.103 & 0.22 \\
\hline & & $\sigma^{*}(\mathrm{C}-\mathrm{O})$ & 0.686 & 1.08 \\
\hline & & $\sigma^{*}(\mathrm{C}-\mathrm{Me})$ & 2.219 & 0.37 \\
\hline & & $\sigma^{*}(\mathrm{C}-\mathrm{C}[$ ring $])$ & 3.183 & 0.54 \\
\hline \multirow[t]{4}{*}{ C6 } & 291.740 & $\sigma^{*}(\mathrm{Me}-\mathrm{C})$ & 2.115 & 0.27 \\
\hline & & $\sigma^{*}(\mathrm{C}-\mathrm{H})$ & 2.223 & 0.31 \\
\hline & & $\sigma^{*}(\mathrm{C}-\mathrm{H}$, del. $)$ & 2.587 & 0.53 \\
\hline & & $\sigma^{*}(\mathrm{C}-\mathrm{H}, \mathrm{del})$. & 3.261 & 0.32 \\
\hline $\mathrm{C} 7$ & 292.404 & $\pi^{*}$ (Ring) & -4.098 & 3.27 \\
\hline \multirow[t]{2}{*}{$\mathrm{C} 8$} & 292.056 & $\pi^{*}$ (Ring) & -4.039 & 3.08 \\
\hline & & $\sigma^{*}(\mathrm{C}-\mathrm{H})$ & 2.074 & 0.35 \\
\hline
\end{tabular}

a. Geometries: All calculated at 4-21G level by GAMESS, except BP, calculated at the 6-31G* level by Spartan.

b. GSCF3 calculation basis set:

Core excited atom: 411121/2111/*

Heavy atoms: $\quad 521 / 31(53 / 4)$

Hydrogen: $\quad 51(6)$ 


\section{Figure and SCHEME Captions}

Scheme 1 Chemical structures of species studied.

Fig. 1 O 1s spectra of hydrogen peroxide [22], t-butyl peroxide [23], benzoic acid (BA), benzoyl peroxide (BP) and [1,3(4)-bis(tertbutylperoxyisopropyl) benzene] (LF) recorded by inner shell electron energy loss spectroscopy (ISEELS) operated in the electric dipole regime ( $2.5 \mathrm{keV}$ final electron energy, $2^{\circ}$ scattering angle). The pre-O1s signal has been extrapolated through the energy range plotted and subtracted. The intensity scale is absolute on a per peroxide bond basis (oscillator strength per two $\mathrm{O}$ atoms). Offsets are used for clarity. The curve labeled 'difference' is the difference of the spectra of $\mathbf{B P}$ and $\mathbf{B A}$.

Fig. $2 \mathrm{O}$ 1s spectrum of hydrogen peroxide [22] in comparison to the result of a GSCF3 calculation. The inset is a plot of the LUMO which shows clearly its $\sigma^{*}$ o-o character.

Fig. 3 (upper) O 1s spectrum of t-BuOH [28] in comparison to the result of a GSCF3 calculation. (lower) $\mathrm{O}$ 1s spectrum of t-butyl peroxide [22] in comparison to the result of a GSCF3 calculation. The insert MO plot clearly shows the $\sigma^{*}$ o-o character of the LUMO. In addition this feature is absent in the spectrum of $\mathrm{t}-\mathrm{BuOH}$, the non-peroxide counterpart.

Fig. 4 (a) O 1s spectrum of solid and gaseous benzoyl peroxide (BP), compared to the results of a GSCF3 calculation for the two symmetry inequivalent $\mathrm{O}$ atoms, along with their sum. (b) Plot of the LUMO showing its $\sigma^{*}{ }_{\mathrm{O}-\mathrm{O}}$ character.

Fig. $5 \mathrm{O}$ 1s spectrum of solid and gaseous 1,3(4)-bis(tertbutylperoxyisopropyl) benzene] (LF) compared to the results of a GSCF3 calculation for the two symmetry inequivalent $\mathrm{O}$ atoms, along with their sum. The MO plots the LUMO in the O1s excited $\mathbf{L F}$, showing a $\sigma^{*}$ o-o character. Only one of the two peroxide bonds in the molecule is shown.

Fig. 6 C 1s spectra of gaseous t-butanol [28], t-butyl peroxide [22], benzoic acid, benzoyl peroxide (BP) and [1,3(4)-bis(tertbutylperoxyisopropyl) benzene] (LF) recorded by ISEELS operated in the electric dipole regime ( $2.5 \mathrm{keV}$ final electron energy, $2^{\circ}$ scattering angle). The pre-C1s signal has been extrapolated through the energy range plotted and subtracted. The intensity scale is absolute on a per carbon basis. Offsets are used for clarity. 
Fig. $7 \mathrm{C}$ 1s spectrum of gas (ISEELS) and solid (NEXAFS) benzoic acid in comparison to the results of a GSCF3 calculation for the five symmetry inequivalent $\mathrm{C}$ atom sites, along with their weighted sum.

Fig. $8 \mathrm{C}$ 1s spectrum of gas (ISEELS) and solid (NEXAFS) benzoyl peroxide (BP) in comparison to the results of a GSCF3 calculation for the five symmetry inequivalent $\mathrm{C}$ atom sites, along with their weighted sum.

Fig. 9 Calculated $\mathrm{O} 1 \mathrm{~s}$ spectra of $\mathrm{HOOH}$ for bond lengths from 137.5 to $157.5 \mathrm{pm}$. 
$\mathrm{H}^{\circ}{ }^{\mathrm{O}} \mathrm{H}$<smiles>CC(C)(C)O</smiles><smiles>O=C(O)c1ccccc1</smiles><smiles>CC(C)(C)O[Ge]OC(C)(C)C</smiles><smiles>O=C(OOC(=O)c1ccccc1)C1=CC=[C+]C=C1</smiles>

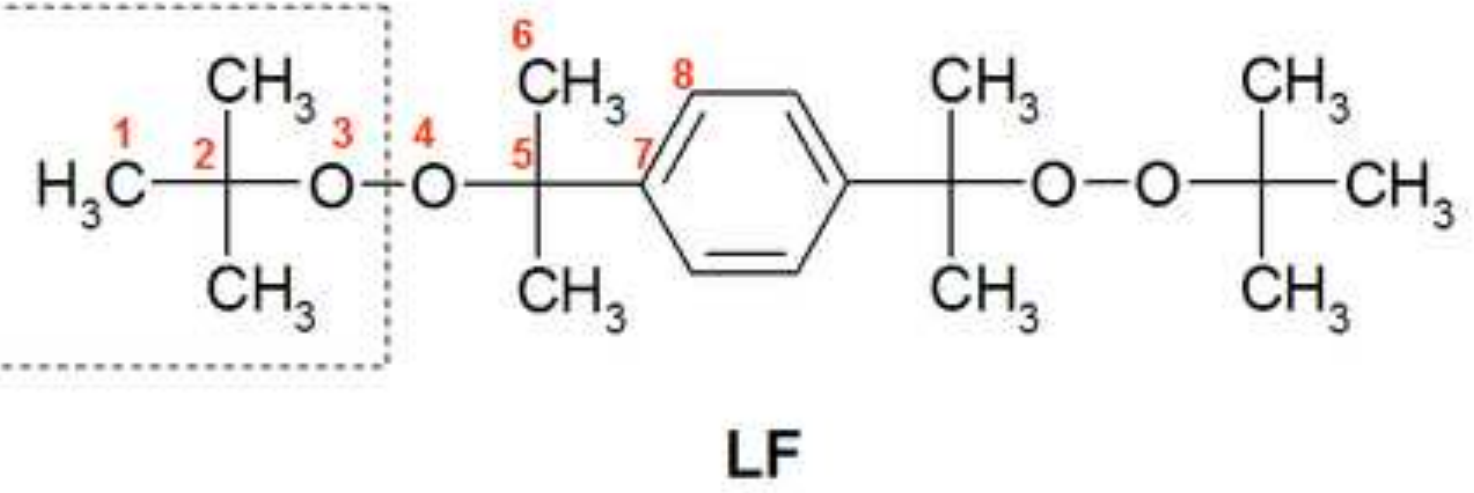




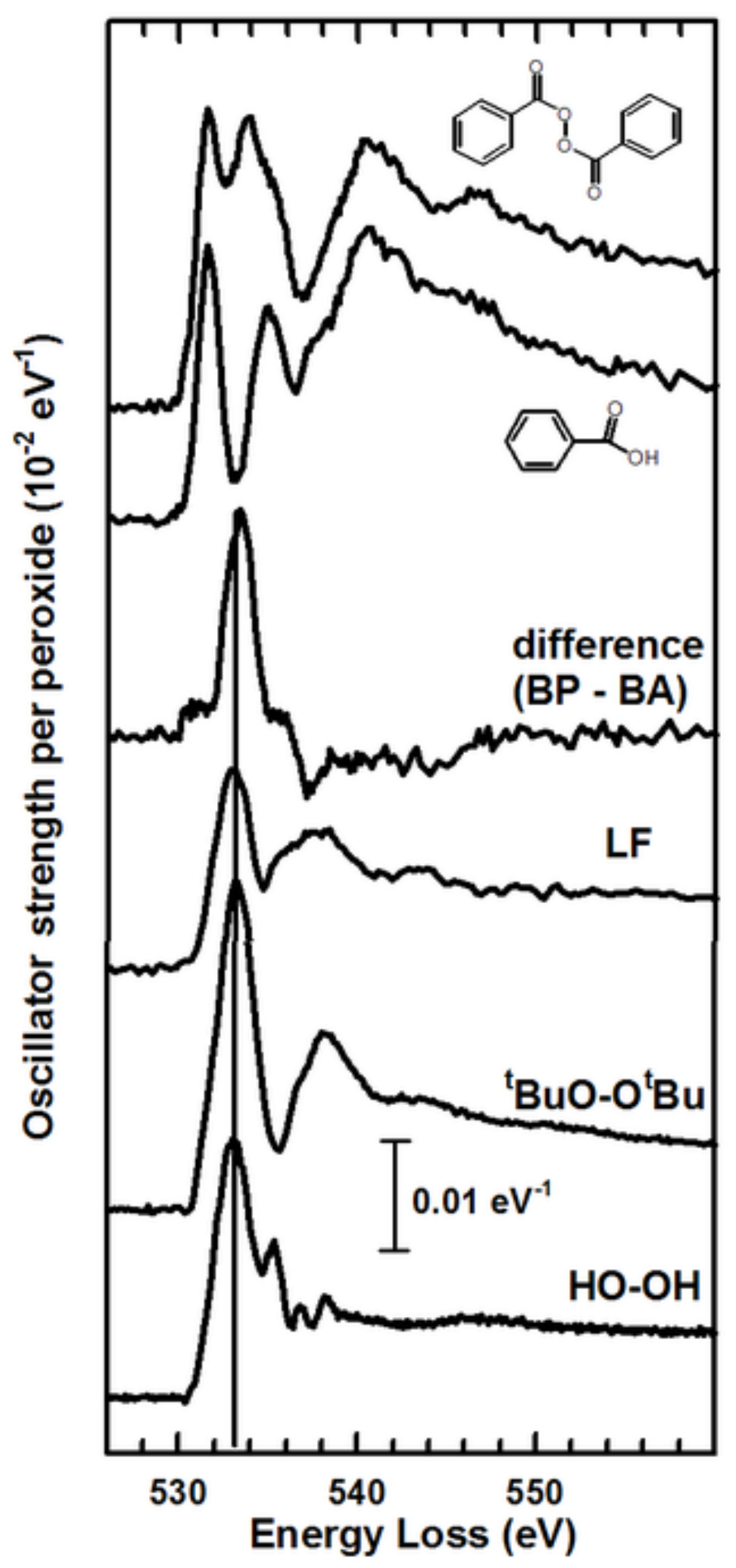

Figure 01 


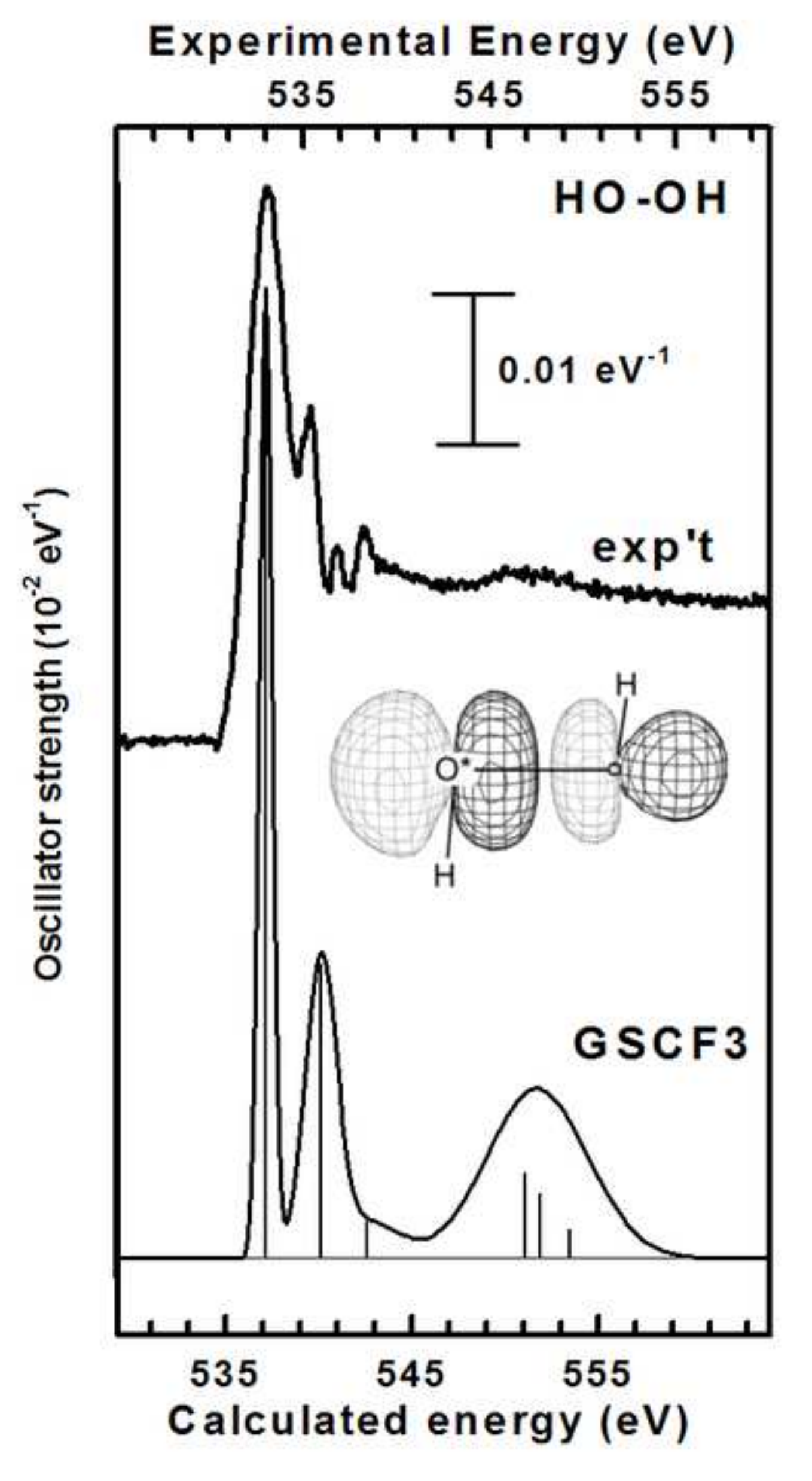

Figure 02

Experimental Energy (eV)

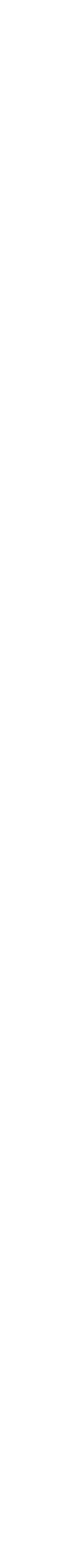

$\begin{array}{lll}535 & 545 & 555\end{array}$

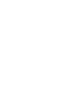
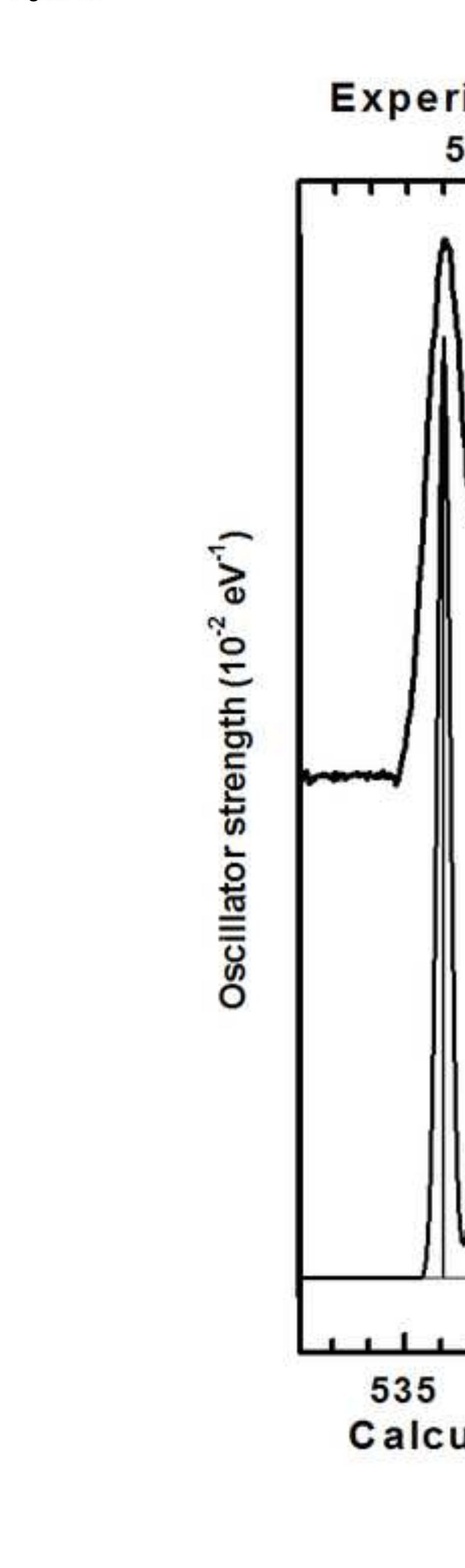
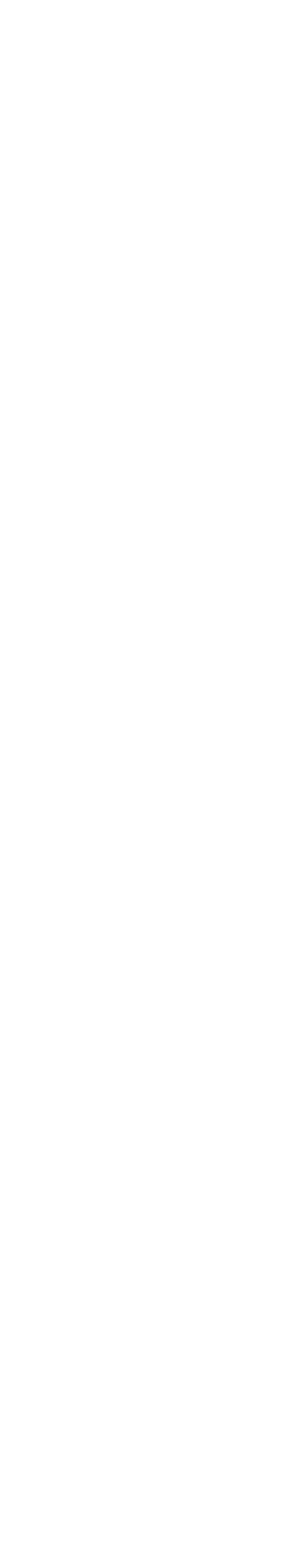


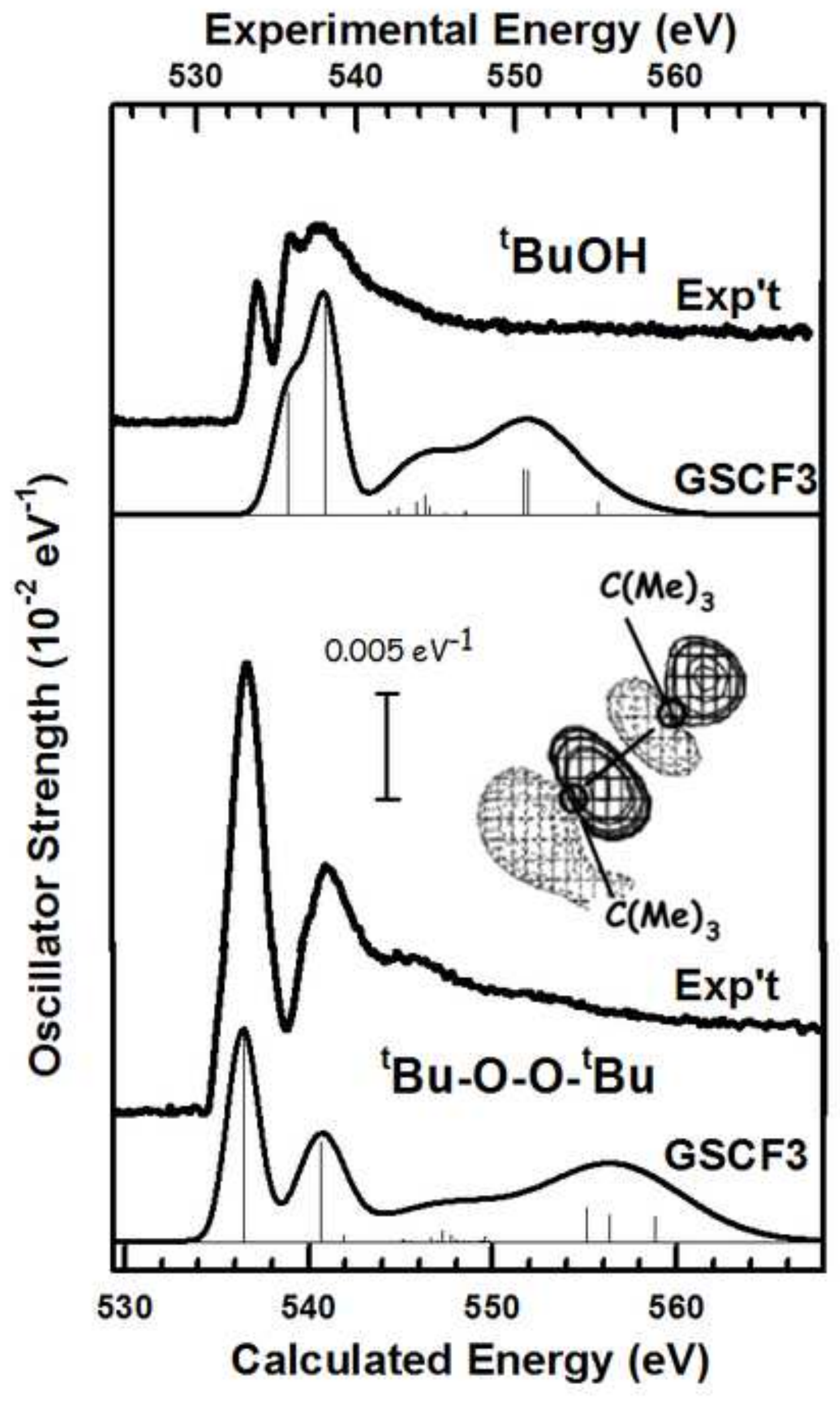

Experimental Energy (eV) 
a

a Experimental Energy (eV)

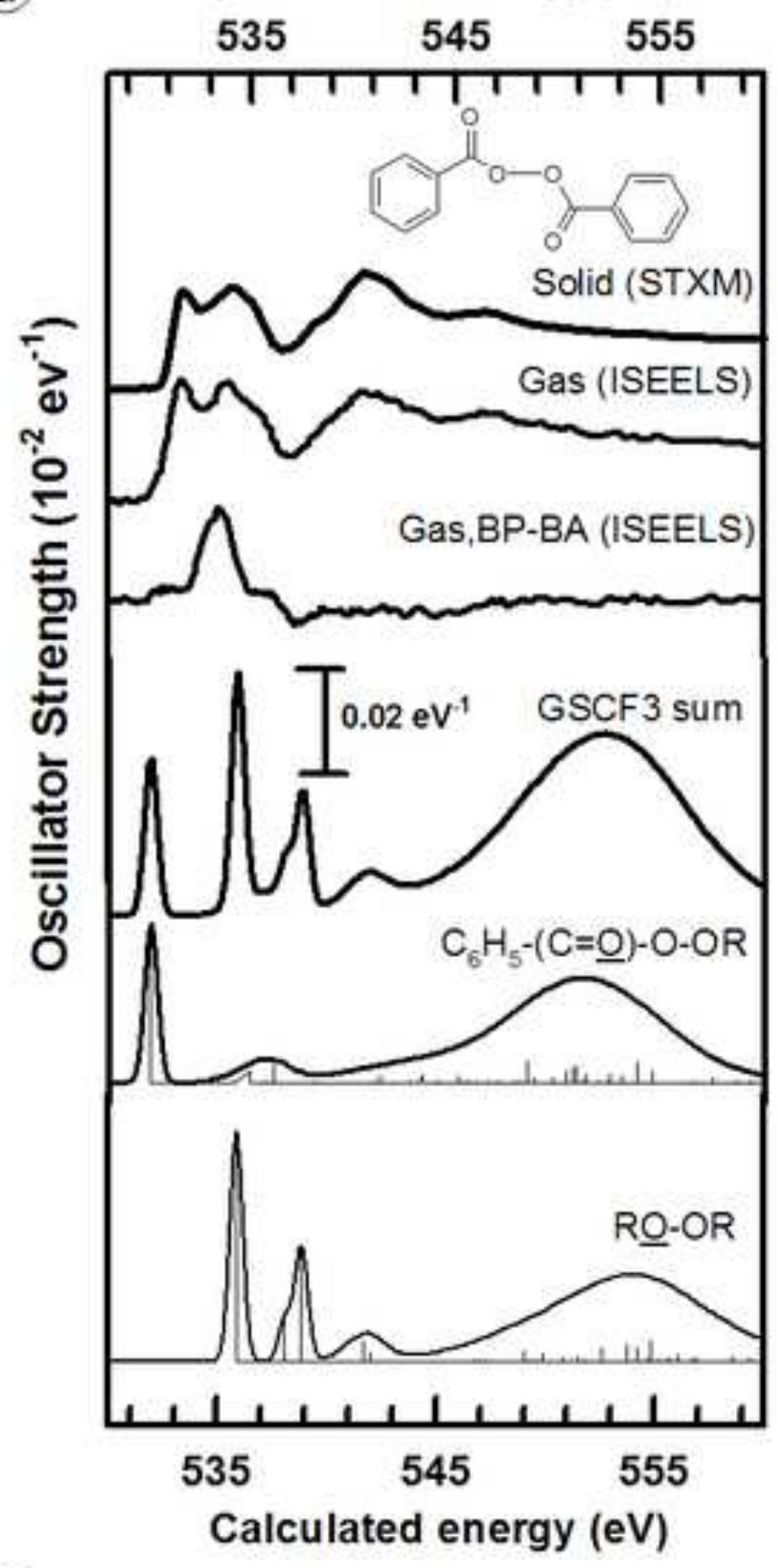

(b)

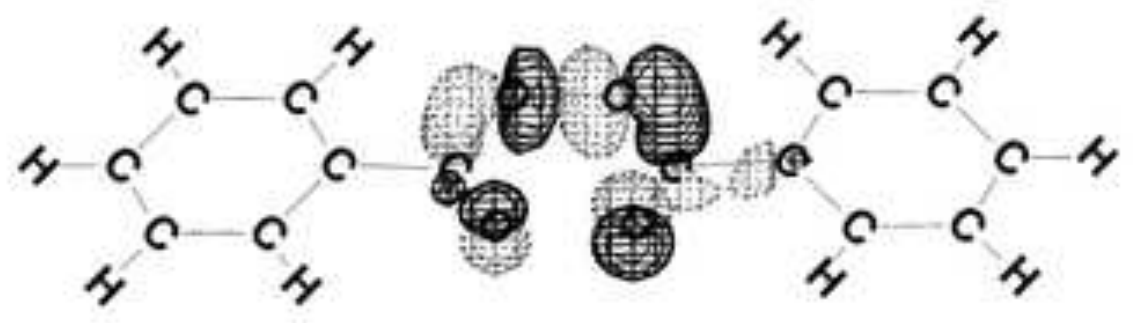




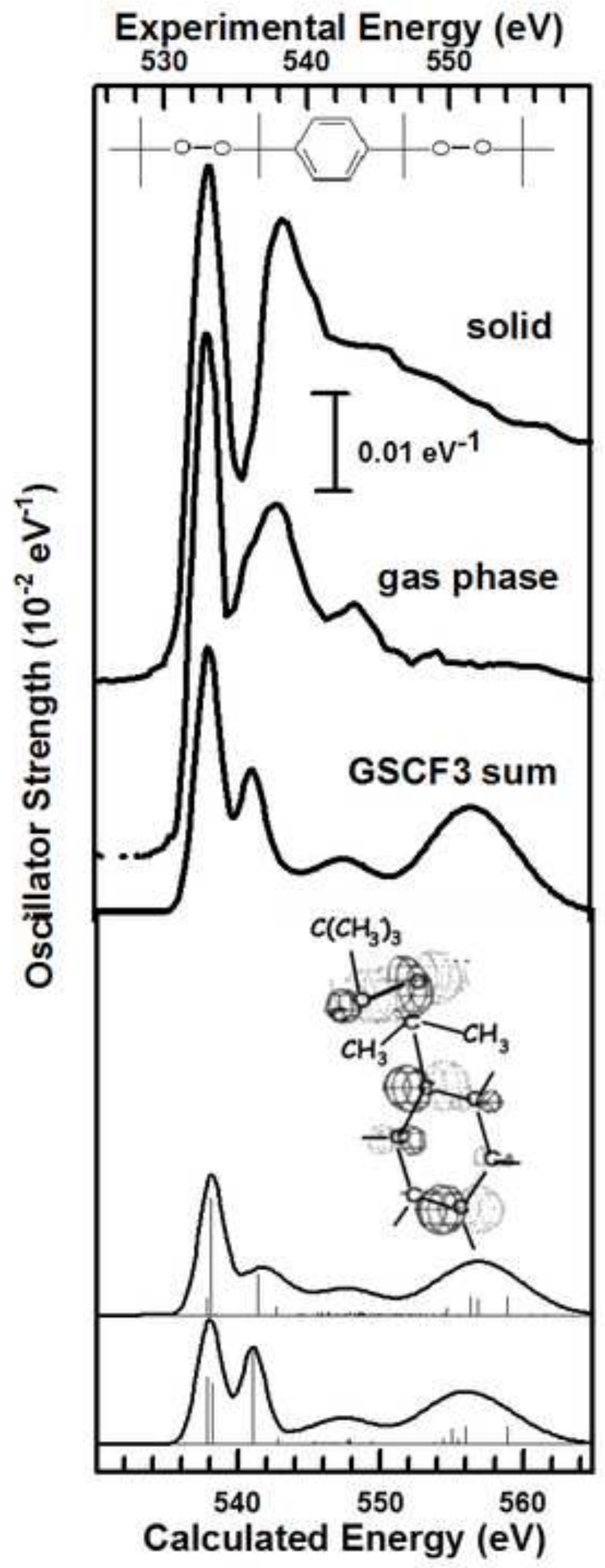




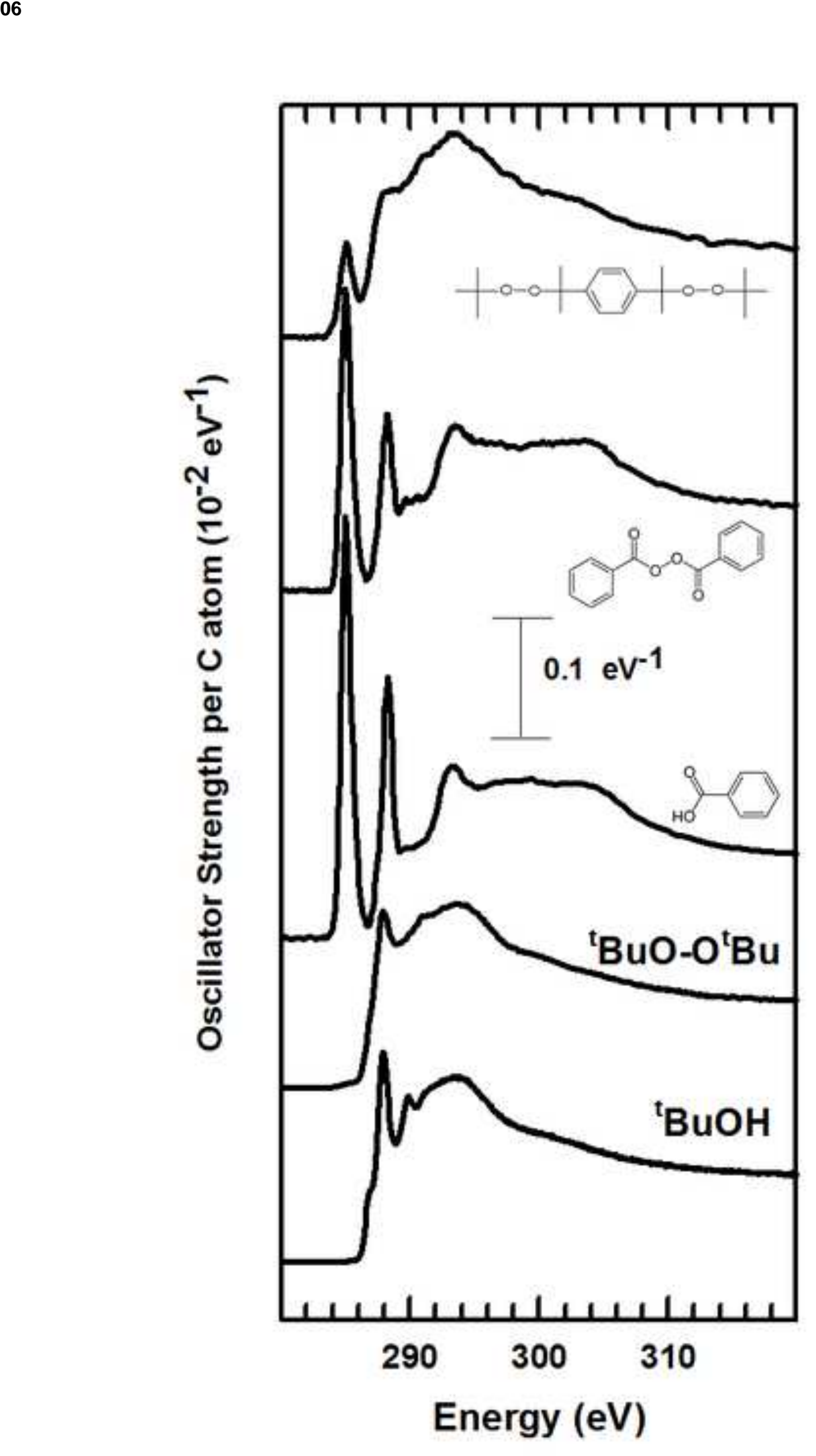

Figure 06

.

Figure 06
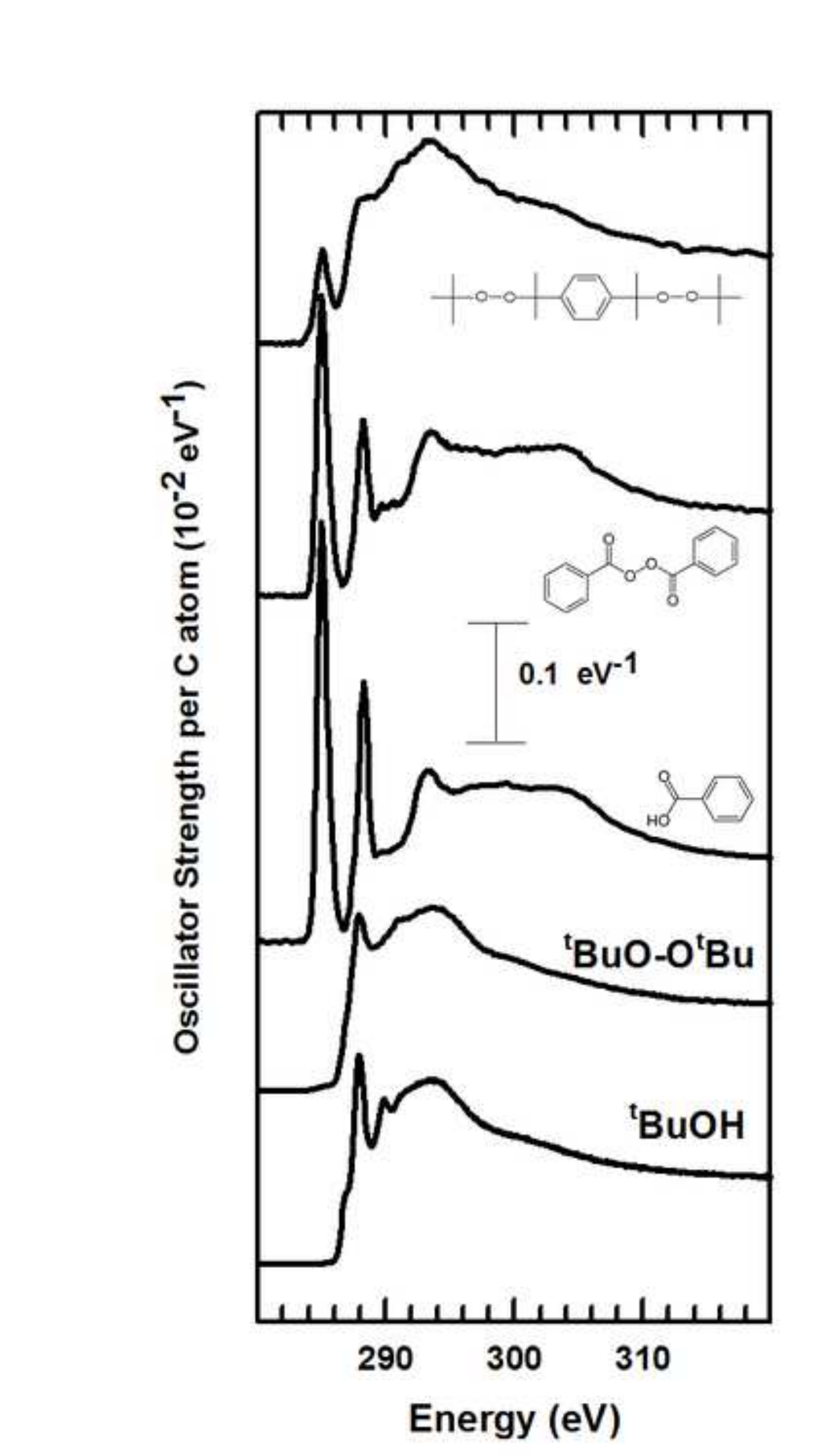

.


Experimental Energy (eV)

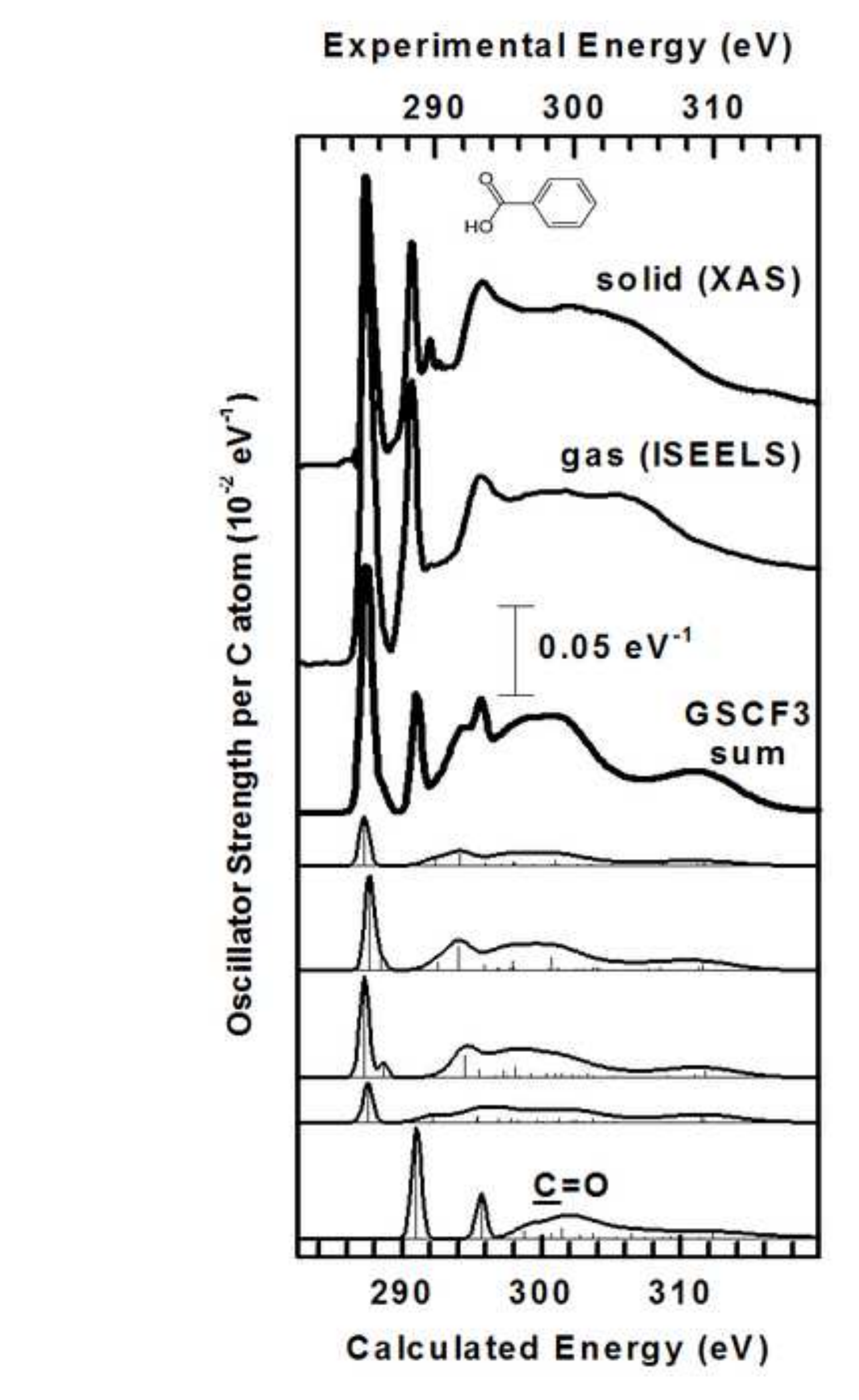

Figure 07

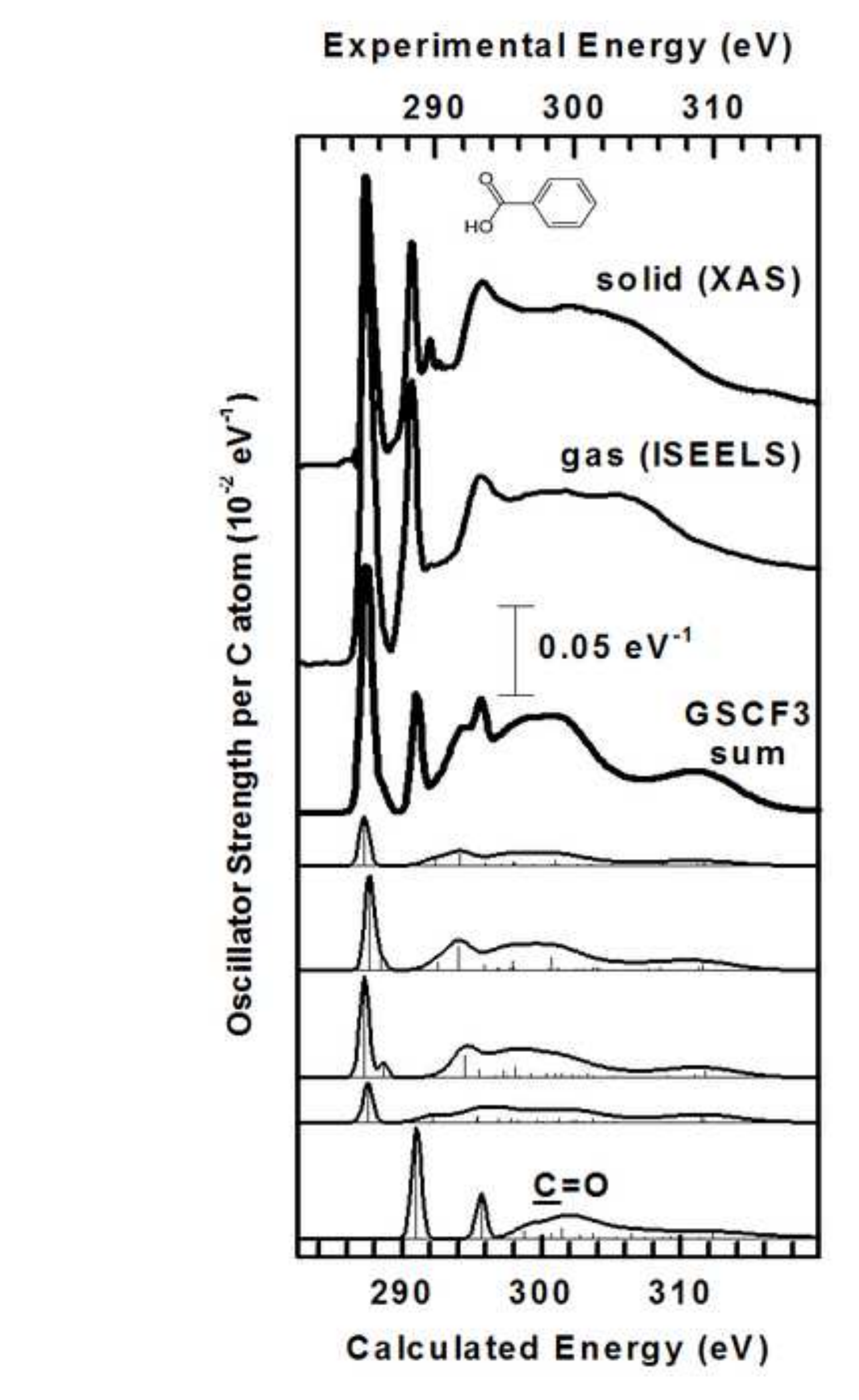

Figure 07

(07




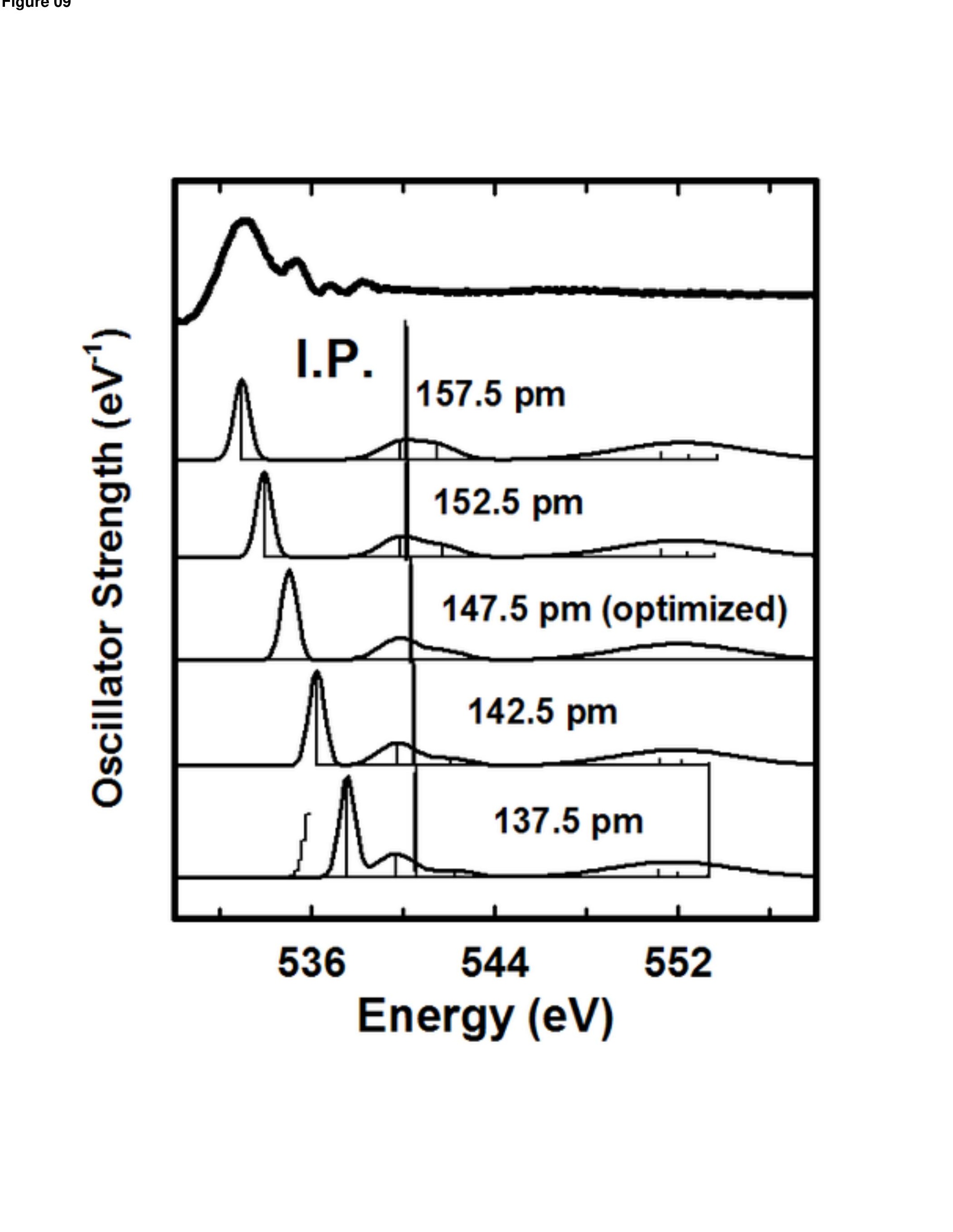

Figure 09

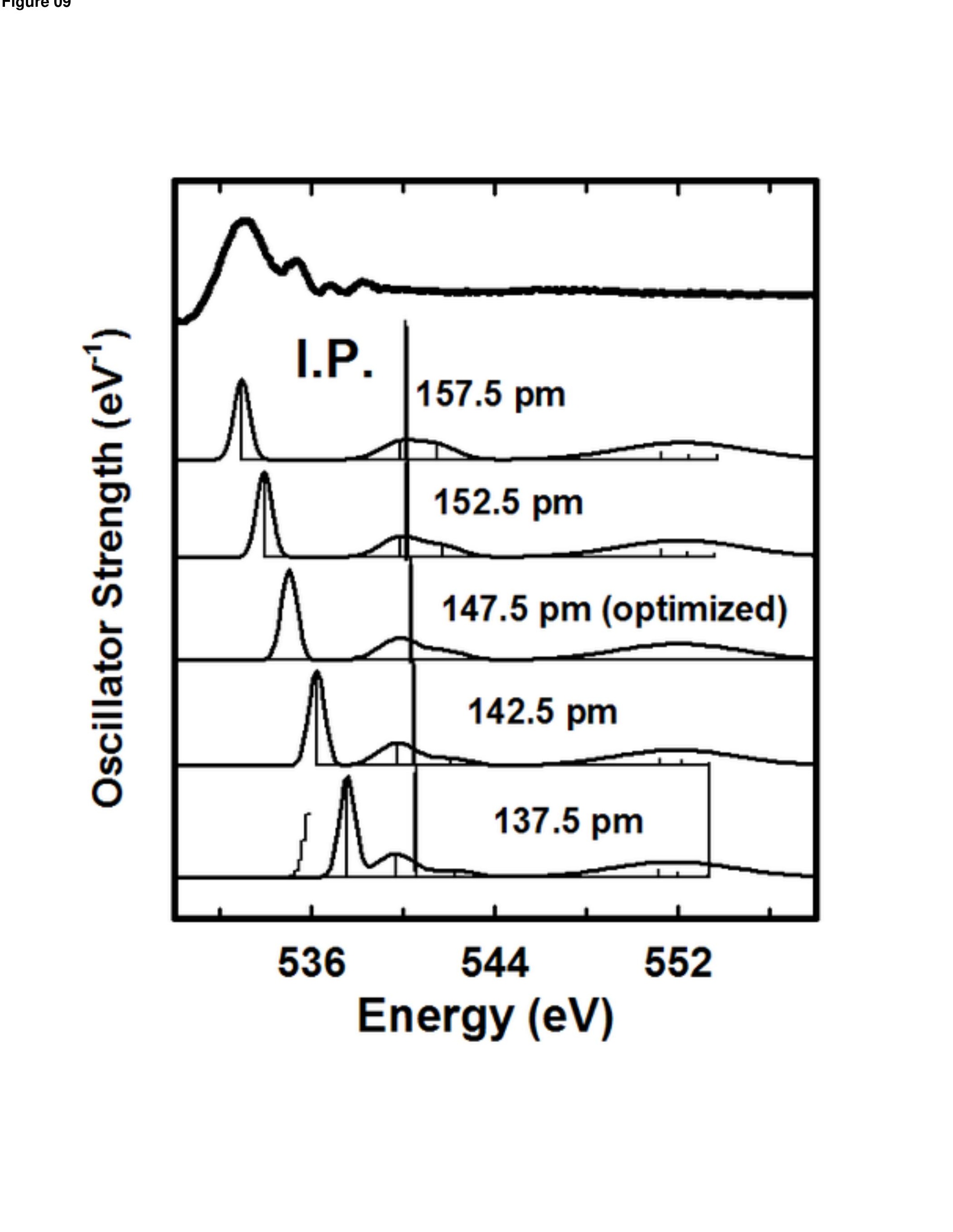




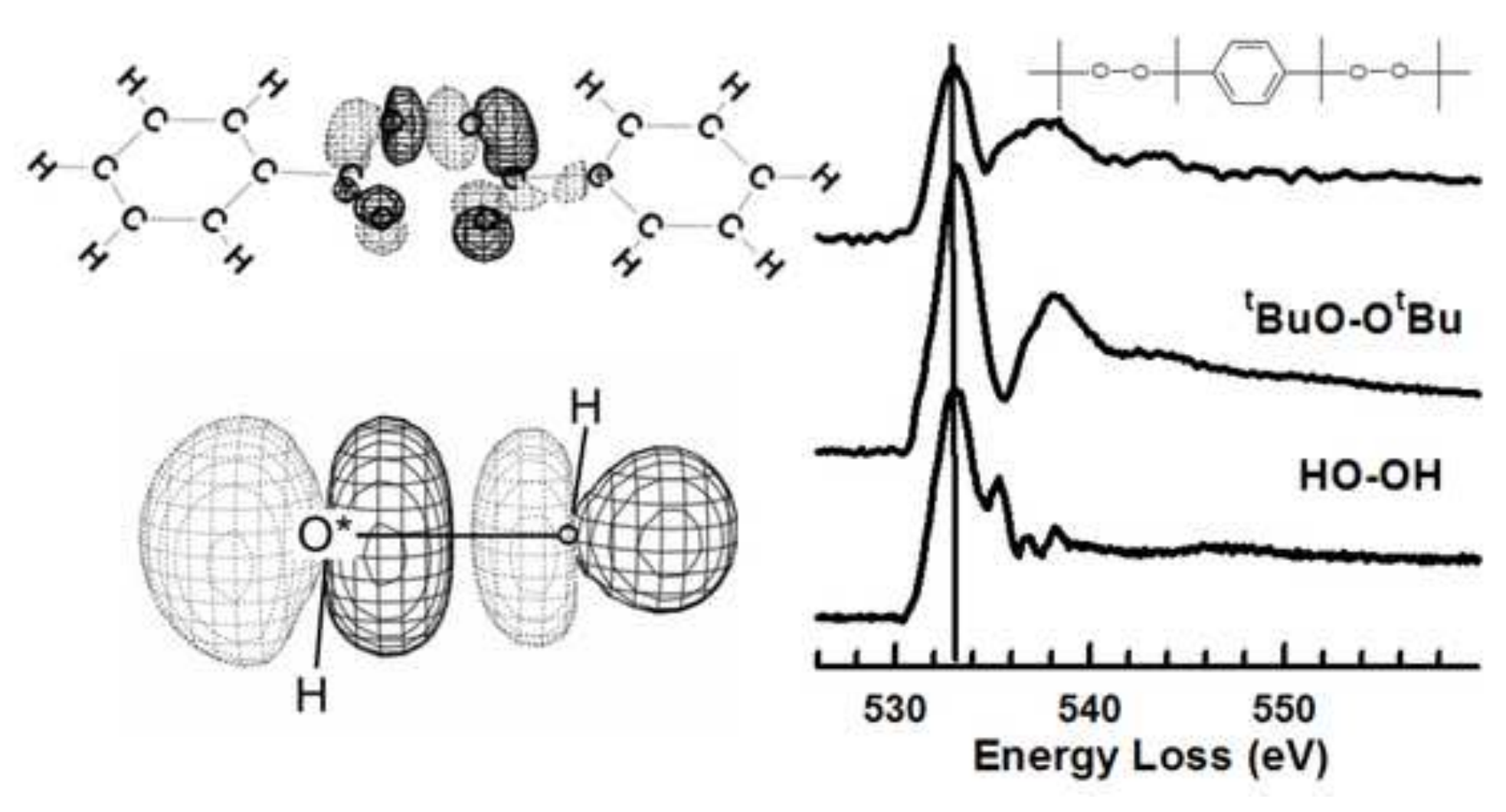

